\title{
Seismic Retrofit of a Multispan Prestressed Concrete Girder Bridge with Friction Pendulum Devices
}

\author{
Alberto Maria Avossa $\mathbb{D D}^{1}{ }^{1}$ Danilo Di Giacinto, ${ }^{1}$ Pasquale Malangone, ${ }^{1}$ and Fabio Rizzo ${ }^{2}$ \\ ${ }^{1}$ Department of Engineering, University of Campania "Luigi Vanvitelli", Aversa, Caserta, Italy \\ ${ }^{2}$ Department of Architecture, University of Chieti-Pescara "G. d'Annunzio", Pescara, Italy \\ Correspondence should be addressed to Alberto Maria Avossa; albertomaria.avossa@unicampania.it
}

Received 23 December 2017; Accepted 4 February 2018; Published 14 March 2018

Academic Editor: Ivo Caliò

Copyright (c) 2018 Alberto Maria Avossa et al. This is an open access article distributed under the Creative Commons Attribution License, which permits unrestricted use, distribution, and reproduction in any medium, provided the original work is properly cited.

\begin{abstract}
The paper deals with the proposal and application of a procedure for the seismic retrofit of an existing multispan prestressed concrete girder bridge defined explicitly for the use of friction pendulum devices as an isolation system placed between piers top and deck. First, the outcomes of the seismic risk assessment of the existing bridge, performed using an incremental noniterative Nonlinear Static Procedure, based on the Capacity Spectrum Method as well as the Inelastic Demand Response Spectra, are described and discussed. Then, a specific multilevel design process, based on a proper application of the hierarchy of strength considerations and the Direct Displacement-Based Design approach, is adopted to dimension the FPD devices. Furthermore, to assess the impact of the FPD nonlinear behaviour on the bridge seismic response, a device model that reproduces the variation of the normal force and friction coefficient, the bidirectional coupling, and the large deformation effects during nonlinear dynamic analyses was used. Finally, the paper examines the effects of the FPD modelling parameters on the behaviour of the retrofitted bridge and assesses its seismic response with the results pointing out the efficiency of the adopted seismic retrofit solution.
\end{abstract}

\section{Introduction}

It is well known that a great portion of the Italian road system has already been built and a remarkable number of existing bridges, currently in exercise on the national road network, were designed and realized without any sort of earthquake resistant criteria. It is, therefore, expected that many of these bridges are highly vulnerable to the seismic actions or can withstand the effects of an earthquake with a lower intensity than the design levels required by some seismic code provisions $[1,2]$. The current efforts being made to protect bridges against earthquakes should, therefore, be focused on minimizing the lateral forces to be carried by the piers. Consequently, seismic isolation could be considered one of the most promising alternatives as a retrofit strategy to improve the seismic performance of existing bridges. In the seismic isolation approach, the superstructure mass is uncoupled from the seismic ground motions using special types of bearings (isolators) which are placed both below the superstructure and on top of the substructure piers and abutments. During a strong earthquake, the isolators add lateral flexibility to the bridge, shifting the vibrational periods of the structures to avoid resonance with the excitations. This allows the superstructure to oscillate at a lower frequency than the piers, thus resulting in large relative displacements across the isolator interface. Those large displacements can be controlled either by incorporating damping elements in the bearing or by adding supplemental dampers. Isolation systems are basically typified into rubber bearings and sliding bearings. Although rubber bearings have been extensively used in base isolation systems, sliding bearings with curved sliding surfaces (friction pendulum device, FPD) have recently found some applications, with several studies having investigated their effectiveness in protecting bridges from damage caused by strong earthquakes. Constantinou et al. [3], Kartoum et al. [4], and Tsopelas et al. [5] conducted experimental studies on bridges isolated by sliding bearings with displacement control devices to real earthquake ground motion applied 
independently in longitudinal and transverse directions. The results of this study demonstrated a substantial improvement in the ability of the isolated bridge to provide for seismic excitation under elastic conditions. Wang et al. [6] developed a systematic method for the nonlinear dynamic analysis of bridges with sliding isolation. Dicleli and Mansour [7] have studied the economic and structural efficiency of the friction pendulum device (FPD) application for retrofitting typical seismically vulnerable bridges in the State of Illinois. Moreover, the effects of ground motion characteristics on the dynamic response and performance of seismically isolated bridges have been evaluated by some authors [8-11].

Along with research on new technology, new design methodologies have also been developed to fulfill the requirements of the performance-based earthquake engineering [12]. Performance levels have been described in terms of displacements since damage is better correlated to displacements rather than forces. Consequently, new design approaches, based on displacements, have been implemented. One of these consists in the Direct DisplacementBased Design (DDBD), proposed by Priestley [13]. The primary goal of DDBD is to design a structure which will exhibit a target displacement profile when subjected to earthquakes consistent with a given reference response spectrum. An early Displacement-Based Design approach for the design of bridge with seismic isolation can also be found in $[14,15]$. An extension of the Displacement-Based Design procedure for bridges simply supported on hysteretic isolation bearings has been proposed by Jara and Casas [16]. Moreover, a Displacement-Based Design (DBD) procedure for continuous decks and multispan simply supported deck bridges equipped with different seismic isolation systems has been proposed by Cardone et al. [17] and Pietra et al. [18].

Within this context, the authors have already proposed a procedure for the seismic retrofit of an existing multispan prestressed concrete road bridge, based on the use of High Damping Rubber Bearing (HDRB) devices as an isolating system placed between pier top and deck [19]. Moreover, the authors presented some preliminary results regarding a similar approach based on the use of friction pendulum device (FPD) for the seismic retrofit of the same case study bridge [20]. In this paper, the authors propose a more comprehensive and updated version of this procedure, defined explicitly for the use of friction pendulum devices (FPD) as an isolating system. Furthermore, the application of the procedure aims to assess and discuss the impact of the FPD device parameters on the seismic retrofitted bridge performance.

As in the previous paper [19], the procedure is firstly based on the preliminary seismic risk assessment of the bridge in existing state carried out using an incremental noniterative approach inspired by the Capacity Spectrum Method and Inelastic Demand Response Spectra proposed by Fajfar [21]. This approach, following the PBEE criteria, allows directly correlating the seismic performance levels to the different intensities of seismic action. Regarding this first part of the procedure, using the same case study of an existing multispan prestressed concrete road bridge, whose structural scheme is also representative of a fairly widespread typology for the construction of road bridges, more specific details are here provided.

Then, the bridge seismic retrofit according to the new seismic actions required by the current Italian Code [2] was achieved by means of a seismic protection strategy based on the use of friction pendulum device (FPD) as an isolating system placed between the top of the substructure elements and the deck. With this aim, a rational approach to the design of curved-surface friction isolators for the seismic rehabilitation of the bridge was proposed and applied. This approach is inspired by the hierarchy of strength considerations as well as the Direct Displacement-Based Design (DDBD) method [14]. Consequently, to assess the impact of the FPD device on the seismic bridge performance, structural models are needed to capture the behaviour of these highly nonlinear elements [22]. Therefore, a model for the FPD that can represent the variation of the normal force, a friction coefficient and rate parameter, bidirectional coupling, and $P-\Delta$ effect during the nonlinear dynamic analyses was used.

Finally, the seismic response of the retrofitted bridge was evaluated by means of nonlinear response history analysis (NRHA). The structural analyses were developed using a new 3D finite element model of the bridge with a consistent damping matrix definition and describing the friction behaviour of the isolators with a viscoplastic model by Constantinou et al. [23]. The outcomes point out the feasibility and efficiency of the retrofit solution adopted and the effect of the FPD modelling parameters on the seismic response of the retrofitted bridge is discussed.

\section{Bridge Geometry and Mechanical Properties}

The case study consists of an existing multispan prestressed concrete girder bridge, as already described in other papers of the authors in $[19,20]$ and here again presented for completeness. The bridge superstructure consists of three spans and two independent decks, respectively, composed of three prestressed concrete girders, with a $\mathrm{V}$ shape, joined by transverse beams as well as a $25 \mathrm{~cm}$ thick upper concrete continuous slab. The substructure columns directly support the deck girders, by means of different bearings types: fixed (F), unidirectional (UL/UT in $X / Y$ directions, resp.), and multidirectional $(\mathrm{M})$. The other structural elements of the bridge, such as the pier and abutment columns and the pile foundation with pile cap, were made of reinforced concrete, with steel reinforcement of yield strength $f_{y}$ higher than $430 \mathrm{MPa}$ (defined as FeB44k in previous Italian Code DM96 [24] and corresponding to ASTM A36 Standard [25]). All the types of concrete used for the bridge structural elements are presented in Table 1.

The geometrical layout of the bridge structural elements, as obtained by the original drawings is represented in Figures $1,2,3$, and 4 , where the plan view of the deck, the lateral views of the overall bridge structure, piers and abutments, and the cross section of the prestressed concrete girder bridge are shown. Observing the layout of the support bearings is possible to identify the lateral load path (Figure 5). In particular, the three columns of the abutment, to whose top the fixed bearing $(\mathrm{F})$ and the two unidirectional transverse 
TABLE 1: Class of concrete used for each structural part.

\begin{tabular}{lcccc}
\hline Structural part & Type & Strength class & $f_{\text {ck,cyl }}[\mathrm{MPa}]$ & $f_{\text {ck,cub }}[\mathrm{MPa}]$ \\
\hline Box girders & Prestressed & $\mathrm{C} 45 / 55$ & 45 & 55 \\
Transverse beams, deck slab & Reinforced & $\mathrm{C} 28 / 35$ & 28 & 35 \\
Columns & Reinforced & $\mathrm{C} 25 / 30$ & 25 & 30 \\
Foundations & Reinforced & $\mathrm{C} 20 / 25$ & 20 & 25 \\
\hline
\end{tabular}

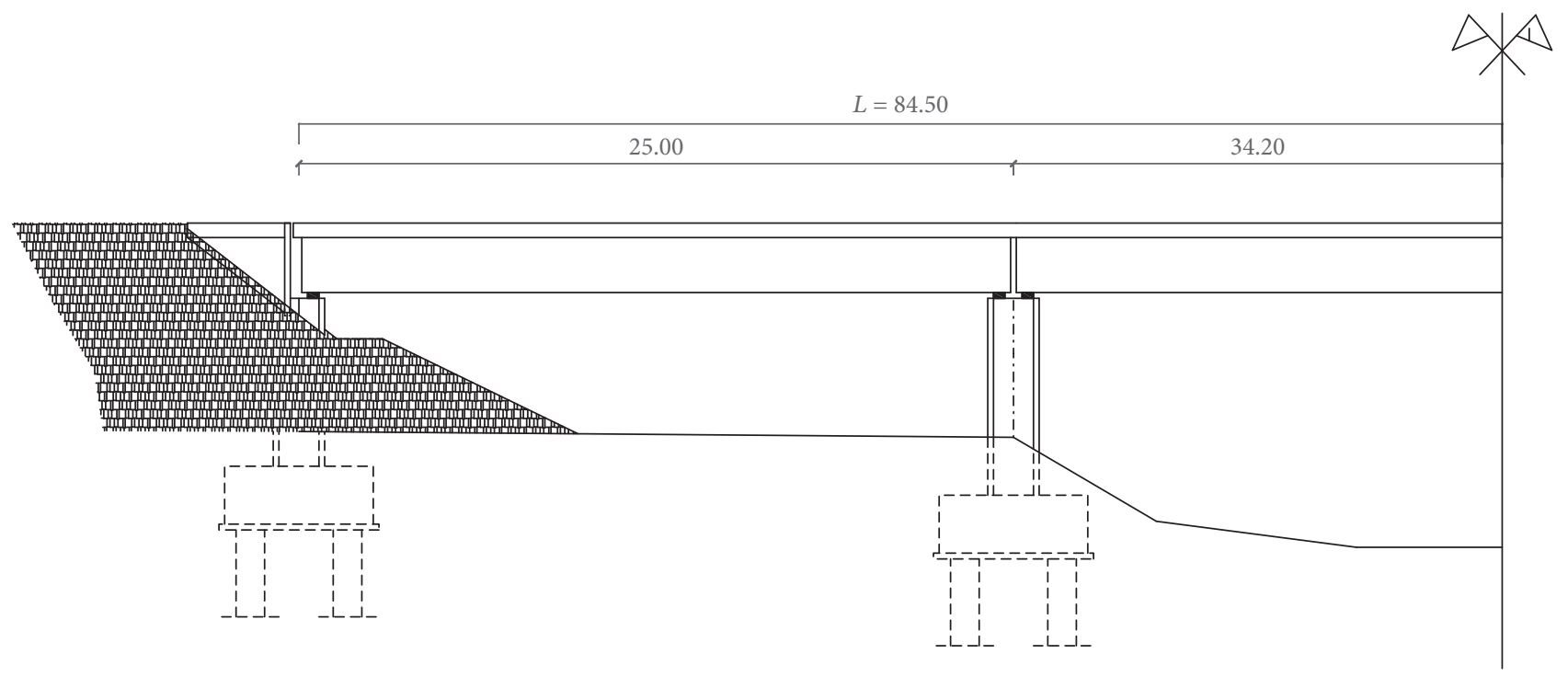

FIgURE 1: Lateral view of the overall bridge structure.

bearings (UT) are located, withstand the lateral loads along the longitudinal $X$ direction. On the other hand, along with the transverse $Y$ direction, the bridge behaves as a frame loaded out of the plane. This is due to the unidirectional longitudinal bearings located at the top of all the central columns.

\section{Seismic Risk Assessment}

3.1. Material Properties. The seismic risk assessment of the existing bridge and the evaluation of their potential structural weaknesses are required before considering any sort of seismic retrofit intervention. Consequently, the seismic vulnerability assessment of the case study bridge structure was developed according to the current Italian Code provisions [2].

Regarding the material properties to be used in the seismic vulnerability assessment, given the high level of uncertainties, a higher safety level must be taken into account applying a Reduction Factor $(\mathrm{RF}=1,0.83,0.74)$ to the mean value of the material properties. This factor is quantified as a function of the Knowledge Levels (KL3, KL2, and KL1), respectively, identified depending on the number of tests and inspections performed on the structure. In particular, for the existing bridges, the Italian Code requires that a high safety level has to be pursued, whereby the KL3 accurate knowledge has to be achieved. In this case, the geometry and the structural details are known from the original outline construction drawings. The information on the mechanical properties of the construction materials is known from original test reports carried out during the building stages. Consequently, the maximum level of knowledge which corresponds to a RF value equal to 1 can be considered. Finally, according to original calculation report, a type $\mathrm{C}$ soil, which refers to deep deposits of dense or medium dense sand, gravel, or stiff clay, with shear wave velocity ranged between 180 and $360 \mathrm{~m} / \mathrm{sec}$, was assumed.

3.2. Structural Model. The structural capacity of the existing bridge was performed using pushover analysis developed on 3D elastic beam-column frame elements with lumped plastic hinges fiber model implemented in SAP2000. In Figure 6, the $3 \mathrm{D}$ view of the structural model and the column base crosssection discretization are shown.

Regarding the superstructure, the prestressed $\mathrm{V}$ shape girders were modelled using three beam elements joined by shell elements outlining the upper concrete slab of the deck. The substructure columns of piers and abutments were modelled by beam-column elements, with lumped plastic hinges placed at base cross section of the columns.

The inelastic behaviour of these lumped plastic hinges, featured by a fiber discretization of the corresponding cross section (Fiber PMM), was defined starting from the materials stress-strain relationship (Figure 6). The stress-strain model, originally proposed by Mander et al. [26] as modified by Saatcioglu and Razvi [27], was used for the concrete, with a compressive strength, $f_{c}$, and the associated strain $\varepsilon_{c}$, equal 


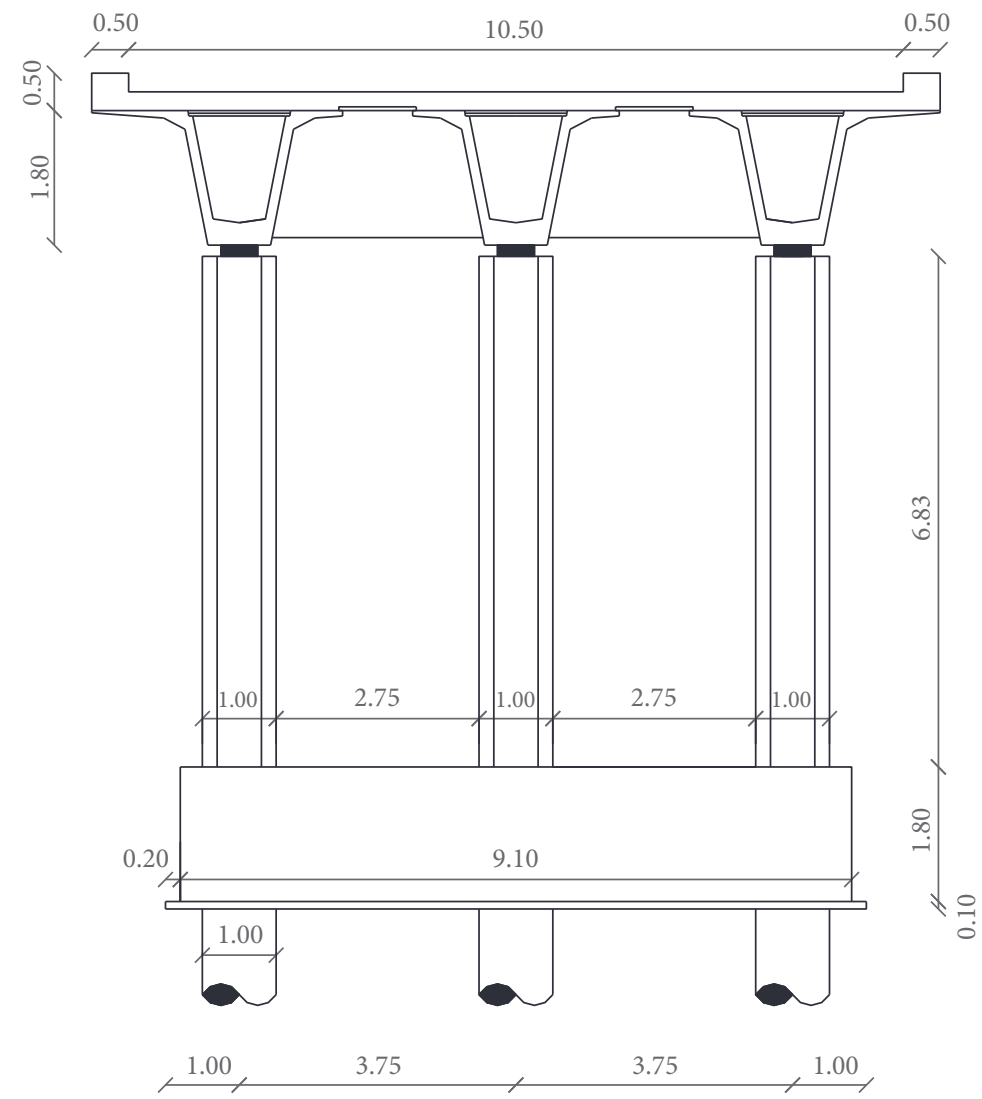

FIGURE 2: Lateral view of the pier columns with cross-section of the deck.

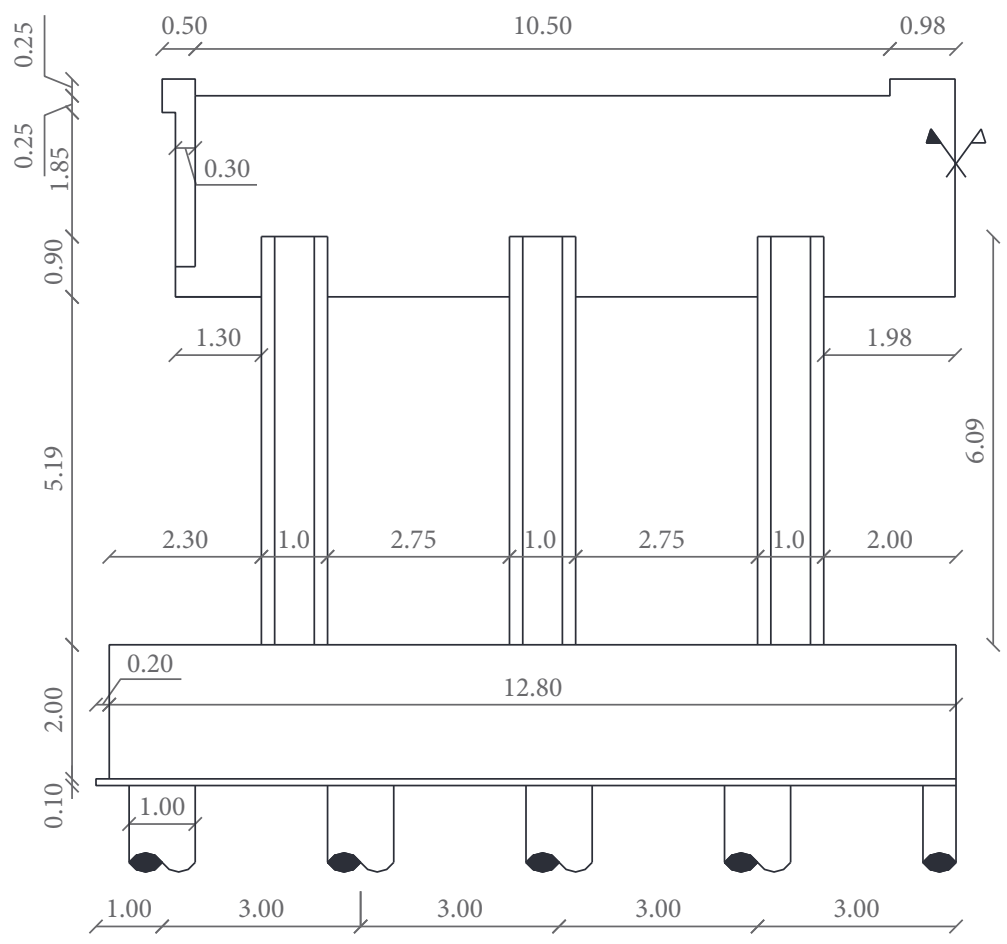

FIgURE 3: Lateral view of the abutment columns. 


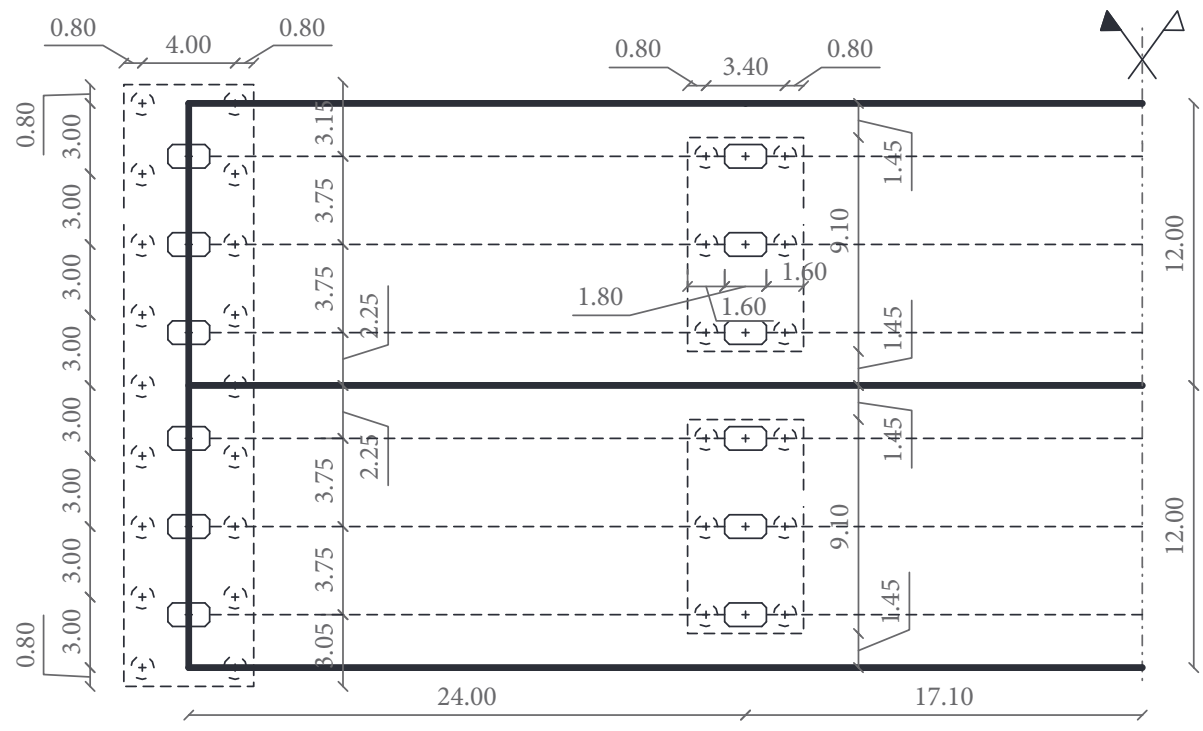

FIGURE 4: Plan view of deck, columns cross-section, and foundations.

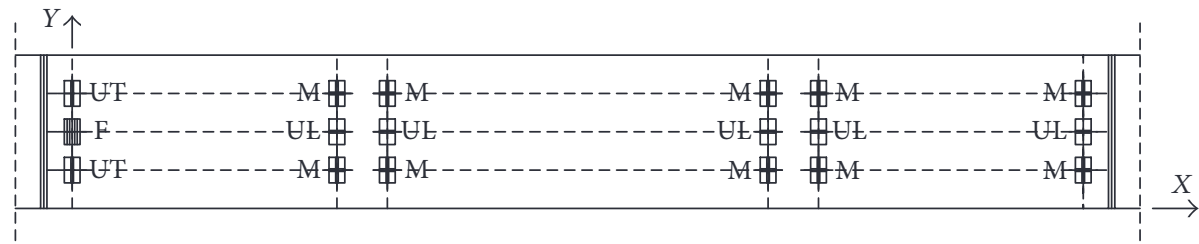
\# Multidirectional bearing (M)
虫 Unidirectional longitudinal bearing (UL)
册 Fixed bearing (F)
世 Unidirectional transverse bearing (UT)

FIGURE 5: Plan layout of the bearings.

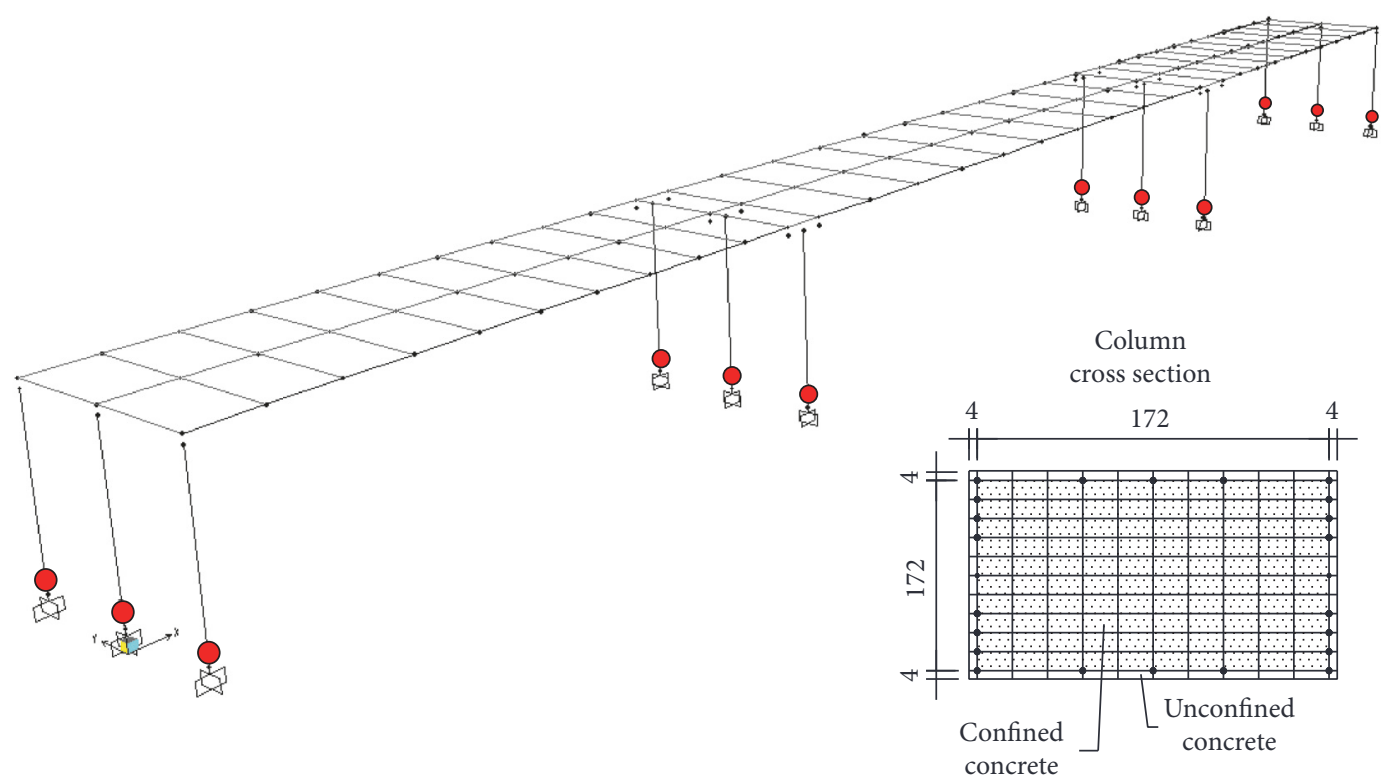

FIgURE 6: 3D view of existing bridge FEM model and column base cross-section discretization. 
to $20.68 \mathrm{MPa}$ and to $2 \cdot 10^{-3}$ for the unconfined case and equal to $25.31 \mathrm{MPa}$ and to $3.96 \cdot 10^{-3}$ for the confined one. The reinforcement steel bars were modelled with an elastoplastic relationship, characterized by an ultimate strain equal to $4 \%$ as suggested by Italian Code [2] for the existing structures. Moreover, the plastic hinges length $L_{P}$ was conservatively assumed equal to 0.1 times the distance $L_{S}$ that is the ratio between the bending moment and the shear of the crosssection at the column base, equal to the column height for a cantilever scheme. The inertial properties of the bridge deck were taken into account through the lumped mass method starting from the discretization of each box girder and span deck. No reduction factor was applied to the cross-section properties of the superstructure and substructure elements due to the anticipated cracking. In fact, the cracking in the box girder, due to the prestressing loads, is prevented, while the effect of the cracking in the column is implicitly taken into account through the inelastic response of the lumped plastic hinges with a fiber discretization of the cross section. The high stiffness of the foundation-soil complex allowed considering the base supports as fixed constraints since the footing flexibility contributes less than $20 \%$ to the pier displacement [28].

3.3. Structural Capacity Evaluation. The capacity curve, which represents the relation between the base shear $\mathrm{V}$ and the lateral displacement $\delta_{\text {TOP }}$ of the control node (usually placed at deck midspan in the case of bridge), was carried out by means of the nonlinear static (pushover) analysis. The pushover analysis was performed in two principal directions (longitudinal $X$ and transverse $Y$ ). A time-independent lateral force profile, corresponding to the fundamental mode, was adopted [29] since the participating mass ratio associated with the first mode in both principal directions is close to $90 \%$. In particular, the first modal shape along the longitudinal and transverse directions are characterized by a period value equal to $0.687 \mathrm{~s}$ and $0.403 \mathrm{~s}$, respectively, with corresponding values of the participating mass ratios equal to $90.2 \%$ and $92.1 \%$. Further details of the dynamical properties of the existing bridges for the other degrees of freedom are reported in [19].

The capacity curve (CC) represents the key issue in the assessment of the structural capacity expressed in terms of global lateral displacement associated with a given Limit State. In particular, the Italian Code [2] suggests that, for existing bridges, the seismic risk assessment has to be fulfilled only for the two Ultimate Limit States: Life Safety (LS) and Collapse Prevention (CP). Consequently, starting from the definition of the yield curvature $\varphi_{y}$ and ultimate curvature $\varphi_{u}$, evaluated by idealizing the moment-curvature relationship of the cross section at column base, the ultimate chord rotation capacity $\theta_{u}(P)$ for a different level of axial force $P$ can be evaluated as the sum of the yield rotation $\theta_{y}(P)$ and the plastic rotation capacity $\theta_{p u}(P)$ expressed as follows:

$$
\begin{aligned}
\theta_{y}(P) & =\frac{\varphi_{y}(P) \cdot L_{S}}{3}, \\
\theta_{p u}(P) & =\left[\varphi_{u}(P)-\varphi_{y}(P)\right] \cdot L_{P} \cdot\left(1-\frac{0.5 L_{P}}{L_{S}}\right) .
\end{aligned}
$$

The bridge structural capacity to the CP Limit State, in terms of global lateral displacement, as marked with the dark square on the capacity curve of Figure $7(\mathrm{a})$, corresponds to the attainment of the shear capacity or bending capacity in the columns. In particular, aiming to the definition of their chord rotation capacity, the target value of ultimate curvature $\theta_{u}$ was detected as the minimum between the values corresponding to the achievement of (a) the maximum allowable strain for the materials; (b) the bending moment equal to the $85 \%$ of its maximum value. The chord rotation capacity associated with the CP Limit State is

$$
\theta_{\mathrm{CP}}=\frac{\theta_{u}(P)}{\gamma_{e l}}
$$

where $\gamma_{e l}$ is a safety factor equal to 1.5 , while the chord rotation capacity $\theta_{\text {LS }}$ associated to the LS Limit State was assumed to be equal to 0.75 times the value calculated for the $\mathrm{CP}$ Limit State. In Figure 7(a), the capacity curves of the existing bridge developed for the two principal directions are shown. The symmetric spatial distribution of stiffness and strength in both the longitudinal and transverse direction permitted to perform a single pushover analysis for each direction.

3.4. Seismic Performance Assessment. The values of the peak ground acceleration $\left(\mathrm{PGA}_{\mathrm{LS}}^{\mathrm{C}} ; \mathrm{PGA}_{\mathrm{CP}}{ }_{\mathrm{CP}}\right.$ ) representing the capacity of the structure for each Limit State were obtained through an incremental noniterative procedure based on the comparison between the structural capacity and the seismic demand, in acceleration-displacement response spectra (ADRS) format. The comparison was carried out using the Capacity Spectrum Method, based on the inelastic demand spectra, originally proposed by Fajfar [21] and then implemented in the procedure reported in Annex B of EC8 as well as in the Italian Code. Starting from the pushover curve, the Capacity Spectrum in ADRS format is obtained by means of the following equations:

$$
\begin{aligned}
& S_{a}=\frac{V}{\alpha_{1} \cdot W_{b}} ; \\
& S_{d}=\frac{\delta_{\mathrm{TOP}}}{\Gamma_{1} \cdot \delta_{D}},
\end{aligned}
$$

where $W_{b}$ is the seismic weight of the bridge, $\alpha_{1}$ is the mass ratio, $\Gamma_{1}$ is the participation factor, and $\delta_{D}$ is the maximum first mode deck displacement. The Capacity Spectrum CS is then approximated with an elastic-perfect-plastic equivalent model (Bilinear Capacity Spectra-BCS) where the elastic stiffness is characterized from the passage for the point of the CS correspondent to $70 \%$ of the yielding acceleration $S_{a y}$. The seismic demand is represented through Inelastic Demand Response Spectra (IDRS) that are indirectly computed scaling the 5\% Damped Elastic Demand Response Spectra (EDRS) defined for each Limit State in Table 2, by the $R-\mu-T$ 


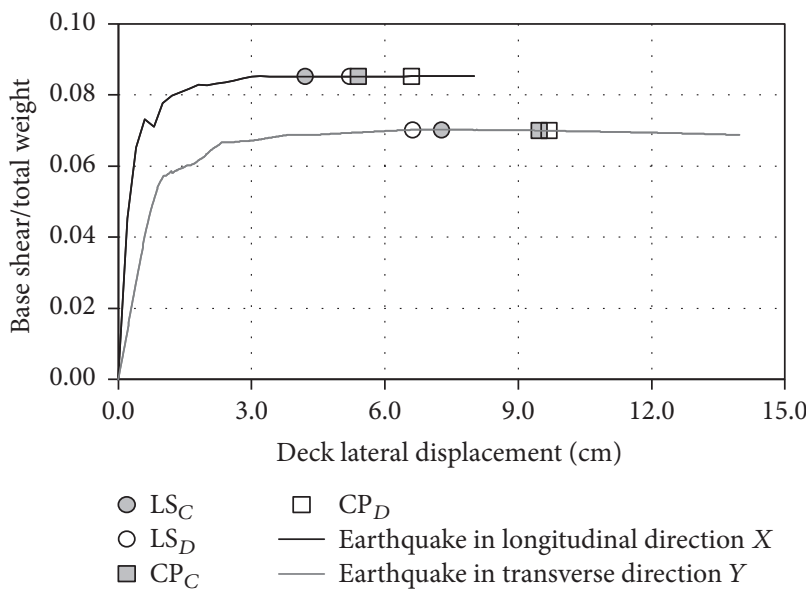

(a)

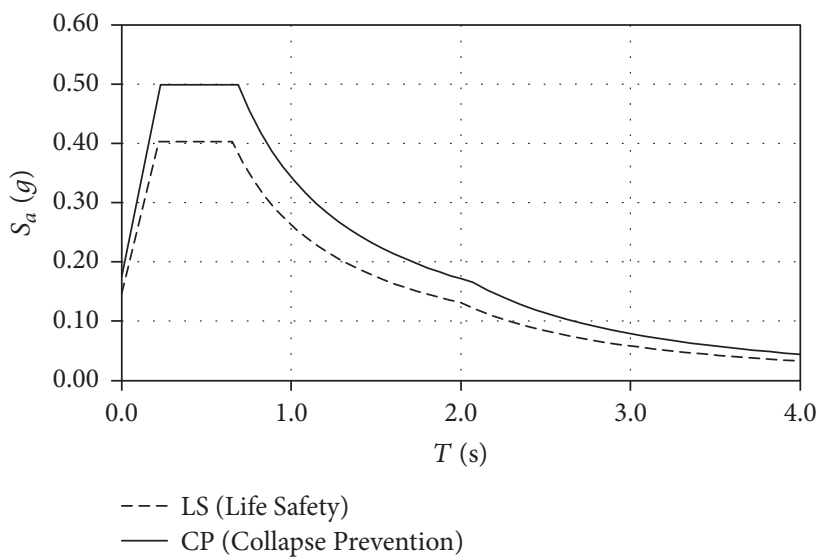

(b)

FIGURE 7: (a) Capacity curves of the existing bridge. (b) Elastic demand response spectra, in terms of acceleration for the LS and CP Limit States defined for the site considered.

relations available in literature for the strength reduction factor proposed by Vidic et al. [30] as follows:

$$
\begin{aligned}
& R_{\mu}=\frac{(\mu-1) T}{T_{0}}+1 \quad \text { for } T \leq T_{0} ; \\
& R_{\mu}=\mu \text { for } T>T_{0} \\
& \quad \text { with } T_{0}=0.65 \cdot \mu^{0.3} \cdot T_{c} \leq T_{c} .
\end{aligned}
$$

In particular, the seismic demand is provided by means of the elastic response spectrum for the horizontal component of the seismic action whose diagram and characteristic parameters are shown in Figure 7(b) and Table 2 respectively. The inelastic pseudo-acceleration $S_{a}$ and displacement $S_{d}$ which represents the coordinates of the IDRS in ADRS format are then derived from the coordinates $\left[S_{d e} ; S_{a e}\right]$ of the EDRS, as follows:

$$
\begin{aligned}
& S_{a}=\frac{S_{a e}}{R_{\mu}} ; \\
& S_{d}=\frac{\mu \cdot S_{d e}}{R_{\mu}} .
\end{aligned}
$$

The reduction factor $R_{\mu}$ depends on the ductility $\mu$ and, therefore, on the lateral displacement of the equivalent SDOF system. Consequently, an iterative graphic procedure is usually required to obtain the intersection between demand (IDRS) and capacity (BCS).

In this case, starting from the target displacements values $d^{C}{ }_{\text {LS }}$ and $d^{C}{ }_{\text {CP }}$ corresponding to the LS and CP Limit States, respectively, the relations between the MDOF system and SDOF equivalent system (see (3)) can be used to correlate the various performance levels with the values of the lateral displacement of the equivalent SDOF system $S_{d, \mathrm{PP}}$. Consequently, it is immediate to characterize the position of the performance point (PP) on the BCS, in the ADRS format, corresponding to the reach of each performance
TABle 2: Parameters of the elastic response spectra, in terms of acceleration for the LS and CP Limit States.

\begin{tabular}{lcc}
\hline Parameter & LS & CP \\
\hline Probability of exceedance $P_{\mathrm{VR}}$ & 0.10 & 0.05 \\
Return period $T_{R}$ (years) & 712 & 1462 \\
Peak ground acceleration $a_{g} / g$ & 0.147 & 0.176 \\
Dynamic amplification factor $F_{0}$ & 2.741 & 2.830 \\
Transition period $T_{C}(\mathrm{sec})$ & 0.651 & 0.687 \\
\hline
\end{tabular}

level. This greatly simplifies the estimation of the intensity levels of the earthquake ground motion corresponding to the various performance levels. In fact, the position of the PP gives the ductility reduction factor $R_{\mu}$ without any iterative procedure. Thus, the problem in convergence and accuracy of the iterative graphical procedures based on the Capacity Spectrum Method may be avoided. For each performance level, the corresponding value of $\mathrm{PGA}^{\mathrm{C}}$ may be calculated with an incremental but noniterative procedure. In fact, the performance point, $\mathrm{PP}$, is fixed, and the earthquake intensity level (PGA) is increased until the IDRS intersects the BCS in PP corresponding to the achievement of its performance level. The outcomes carried out applying this NSP procedure, reported in Tables 3 and 4, consist in the evaluation of the capacity of the existing bridge to resist seismic actions in terms of peak ground acceleration PGA values corresponding to the Ultimate Limit States of the structure $\left(\mathrm{PGA}_{\mathrm{LS}}^{\mathrm{C}}\right.$; $\mathrm{PGA}^{\mathrm{C}}{ }_{\mathrm{CP}}$ ). On the other hand, the PGA values required for the LS and CP Limit States $\left(\mathrm{PGA}^{D}{ }_{\mathrm{LS}} ; \mathrm{PGA}_{\mathrm{CP}}{ }_{\mathrm{CP}}\right)$ correspond to the seismic demand for a return period of 712 years and 1462 years, respectively. Consequently, the seismic risk indices are defined by the capacity/demand ratios as

$$
\begin{aligned}
\alpha_{\mathrm{LS}} & =\frac{\mathrm{PGA}_{\mathrm{LS}}}{\mathrm{PGA}_{\mathrm{LS}}^{D}} ; \\
\alpha_{\mathrm{CP}} & =\frac{\mathrm{PGA}_{\mathrm{CP}}}{\mathrm{PGA}_{\mathrm{CP}}^{D_{\mathrm{CP}}}} .
\end{aligned}
$$




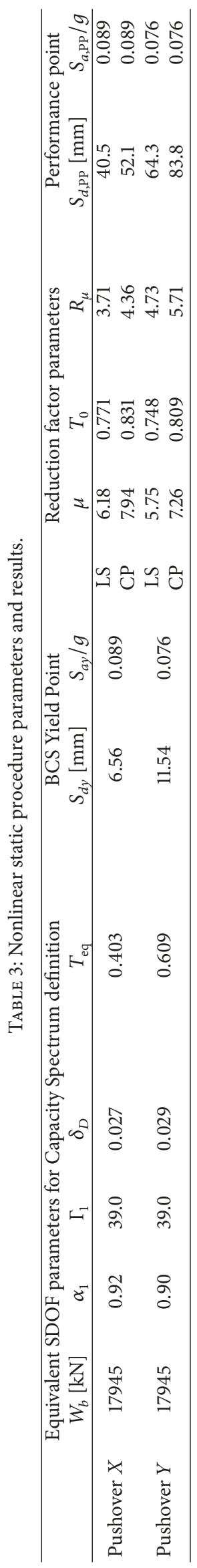


TABLE 4: Capacity and demand peak ground acceleration and corresponding risk index.

\begin{tabular}{lcccccc}
\hline Direction & $\mathrm{PGA}_{\text {LS }}^{C}$ & PGA $_{\text {CP }}^{C}$ & PGA $_{\text {LS }}^{D}$ & PGA $_{\text {CP }}^{D}$ & $\alpha_{\text {LS }}$ & $\alpha_{\mathrm{CP}}$ \\
\hline Longitudinal $X$ & 0.121 & 0.138 & 0.147 & 0.176 & 0.823 & 0.784 \\
Transverse $Y$ & 0.168 & 0.170 & 0.147 & 0.176 & 1.143 & 0.966 \\
\hline
\end{tabular}

The values of the seismic risk index evaluated for the Life Safety and the Collapse Prevention Limit States along the longitudinal and transverse directions are also listed in Table 4 . A value of the capacity/demand ratio greater than one points out that the bridge in existing state fulfills the seismic performance required for a given Limit State. The condition for which the verification is fulfilled occurs only for the case of the LS Limit State and seismic loads acting along the transverse direction. The other capacity/demand ratios for the LS Limit State along the longitudinal direction as well as for the CP Limit State along the two principal directions are less than one. These outcomes point out the poor lateral displacement capacity and limited global ductility of the existing bridge if compared to the new "seismic demand" levels required by the code provisions. These results are mainly due to the low chord rotation capacity of the plastic hinges located at base cross section of the columns.

\section{Seismic Retrofit}

4.1. Intervention Strategy. As an alternative to the use of some traditional intervention approaches, the improvement of the seismic performance of the existing bridge was developed through a retrofit strategy based on seismic isolation and supplemental energy dissipation. To this aim, the use of friction pendulum devices (FPD) placed between the piers top and the deck was developed. This strategy is highly convenient from an economic point of view if compared to those of a maintenance intervention for the replacement of the bearing devices. In fact, if the seismic isolation has a high typically premium due to the high cost of the bearing devices and construction of additional elements required for the connection between the bridge deck and substructure, it presents economic benefits due to the reduction of postearthquake repair costs.

4.2. Friction Pendulum Devices. Seismic isolation represents a useful tool for the earthquake resistant design of bridges that can be used in both new constructions and retrofits $[6,15,17$, $19,20,31]$. The friction pendulum device (FPD) [32] is seismic isolation bearing, with a mechanism based on its concave geometry and surface friction properties (Figure 8) [33]. The supporting structure is governed by a pendulum motion as the housing plate simultaneously slides on the concave spherical surface and dissipates hysteretic energy via friction [34].

For a single concave isolator pendulum with a radius of curvature $R_{C}$ and weight $W$, the following relations can express the period of vibration $T_{P}$ after the activation of FPD isolator and the associated stiffness $K_{P}$ :

$$
T_{P}=2 \pi \sqrt{\frac{R_{C}}{g}} ;
$$

$$
K_{P}=\frac{W}{R_{C}},
$$

where $g$ is the gravity acceleration. Therefore, the forcedisplacement diagram of a FPD isolator is nearly rigid due to stick-slip behaviour, for lateral loads lower than the resisting friction force $V_{f}$ and proportional to $K_{P}$ for higher loads (Figure 8). In particular, $V_{f}$ expresses the intersection of the curve with the $Y$-axis (corresponding to zero displacement) and is calculated as the product of the friction coefficient $\mu_{F}$ times the supported load $W$ :

$$
V_{f}=\mu_{F} W .
$$

The fundamental design parameters of a FPD device are the material friction coefficient and the radius of curvature. Noticeably, there is little control of the friction coefficient, which can typically range between 0.02 and 0.11 depending on the material properties used for the construction of the sliding surfaces, the changes with contact pressure, sliding velocity, air temperature, and so on [35].

The radius of curvature in principle is free of restriction parameter. Nevertheless, its value is only limited by the condition to have not a much larger value of the structural vibration period which is related to a very low lateral stiffness of the isolated structure and/or potential maximum residual displacement. Moreover, regarding the displacement capacity $\Delta_{m}$ of the FPD isolator, there is no theoretical restriction except for the inherent limits on the uplift. Subsequently, the energy dissipation property of the FPD devices may be assessed by evaluating the equivalent viscous damping ratio $\xi_{\mathrm{FP}}$ starting from the area of a full hysteresis loop $A_{h}$ :

$$
A_{h}=4 \mu_{F} W \Delta_{m} .
$$

Whereas the maximum lateral force $V_{m}$ is equal to

$$
V_{m}=W\left(\mu_{F}+\frac{\Delta_{m}}{R_{C}}\right)
$$

the $\xi_{\mathrm{FP}}$ value can be estimated as follows:

$$
\xi_{\mathrm{FP}}=\frac{2 \mu_{F}}{\pi\left(\mu_{F}+\Delta_{m} / R_{C}\right)} .
$$

As mentioned above, the behaviour of the FPD is strongly nonlinear and involves the coupling of multiple components of the dynamic response, posing challenges for those attempting to model their response. The main modelling aspects of the response of the FPD are (1) the normal force $(W)$; (2) the coefficient of friction $(\mu)$; (3) the in-plane bidirectional sliding interaction; and (4) large deformation effects $(P-\Delta)$. The response of the FPD is typically modelled by a simplified bilinear force-deformation relationship. Ample theoretical and experimental research findings are available in the current literature, separately representing each of these modelling aspects.

Experiments have shown that axial load fluctuations were consequential in the response of individual isolators incorporating a sliding mechanism [36, 37]. Dicleli showed that varying dead loads on the FPD along a seismically isolated bridge, 


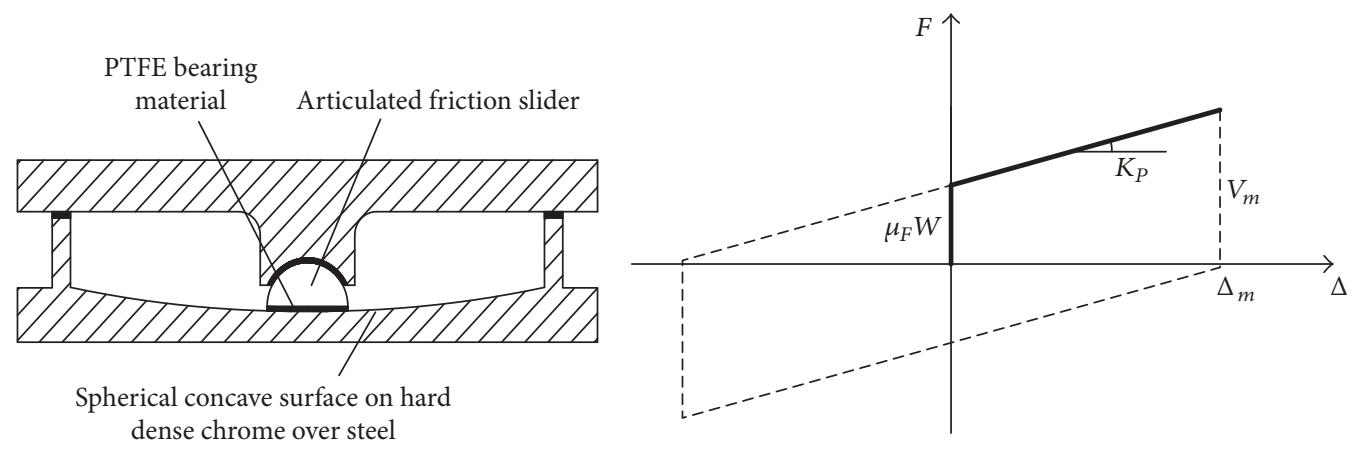

FIGURE 8: Scheme and hysteresis loop of a FPD isolator.

due to a different tributary weight on abutments and piers, might lead to a nonuniform transverse response that could result in excessive displacements [38]. Jangid performed a parametric study on a Seismic Isolation Bridge and showed that the friction coefficient of the bearings is influential in optimizing the seismic response of the bridge [39].

In particular, the coefficient of friction $\mu$, in addition to the material properties of the surface, were found to be primarily a function of the slider velocity $v$ and axial force $N$ [40]. Accurate mathematical models have been developed by Constantinou et al. [41] to capture the value of $\mu$ for a range of $v$ that is of interest to the response of the FPD. The influence of $v$ on $\mu_{F}$ was approximated via the aid of the experimental results as follows:

$$
\mu_{F}=\mu_{\text {fast }}-\left(\mu_{\text {fast }}-\mu_{\text {slow }}\right) e^{-r v},
$$

where $\mu_{\text {fast }}$ and $\mu_{\text {slow }}$ are the values of the friction coefficient at large and small sliding velocities, respectively, and $r$ is a rate parameter, having units of time per unit length, that controls the variation of the coefficient of friction with velocity (Figure 9). The parameters used in defining (12) are mainly functions of surface properties and contact pressure. Sample values may be found elsewhere [42, 43].

The comparison between the experimental and numerical results relating to the values of the friction coefficient depending on different axial stress levels and the rate parameter $r$ variation are shown in Figures 9(a) and 9(b), respectively. Moreover, Warn and Whittaker [44] showed that neglecting the bidirectional coupling of the isolation bearing models in bridges resulted in discrepancies in the force-deformation histories and underestimation of displacements of the bearings. Almazan and De la Llera [45] showed that the exact kinematics and $P-\Delta$ moments might be considerable in estimating the peak bending moments of the columns in seismically isolated bridges. The authors highlighted that the upward or downward positioning of the FPD can be used to control the flow of the $P-\Delta$ moments.

It is, therefore, clear that to properly assess the seismic response of bridge structures isolated with friction pendulum device; it is necessary to take into account all of the modelling aspects mentioned.

4.3. Bridge Retrofit Design Process. For the case study of existing bridge, a seismic retrofit strategy based on the use of an isolating system located between the columns top and the deck was implemented through the placement of a FPD single concave isolator in place of the existing support bearings (18 devices). Moreover, the application of a seismic isolation strategy permits controlling the seismic response of the substructure elements without increasing their lateral strength and stiffness [46]. The design of the FPD isolators was performed by means of a multiobjective approach in order to meet the performance levels provided for different operating conditions of the bridge. In particular, the first design objective was to avoid the deck displacements under the lateral actions due to wind loads and braking forces defined according to the Serviceability Limit State SLS level. On the other hand, the second design objective was to ensure that the seismic response of the columns of the piers and abutments kept within linear elastic range when the deck achieved the maximum lateral displacement demand provided by the seismic code for the Ultimate Limit State SLU level.

The first design level allows designing the minimum value of the static friction coefficient $\mu_{\text {stat }}$ required to avoid the lateral displacement of the deck under the effect of the lowlevel horizontal loads. This objective is pursued by verifying the following condition:

$$
\mu_{\text {stat }} \cdot W_{\text {tot }} \geq F_{b} \longrightarrow \mu_{\text {stat }} \geq 0.03,
$$

for which the design target is reached if the sum of the friction forces of all the devices $\left(W_{\text {tot }}=14629 \mathrm{kN}\right)$, calculated when the minimum axial load acts on each device, exceeds the maximum value of the horizontal forces $F_{b}$ due to longitudinal braking and acceleration effect of the vehicles acting at the surfacing level of the carriageway equal to $442 \mathrm{kN}$.

The second design level was performed through a design process consisting of an application of a Direct DisplacementBased Design (DDBD) approach as well as the hierarchy of strength considerations to define first the displacement capacity $\Delta_{m}$ and then the radius of curvature $R_{C}$ of the isolators. It is well known that the DDBD approach aims to design a structure to achieve a predefined level of lateral deformation under a target level of earthquake intensity [14]. Moreover, the application of the displacement-based concepts for assessment and evaluation of existing structures is more straightforward since the characteristics of the structure, such as material properties and elements geometry, are known. 


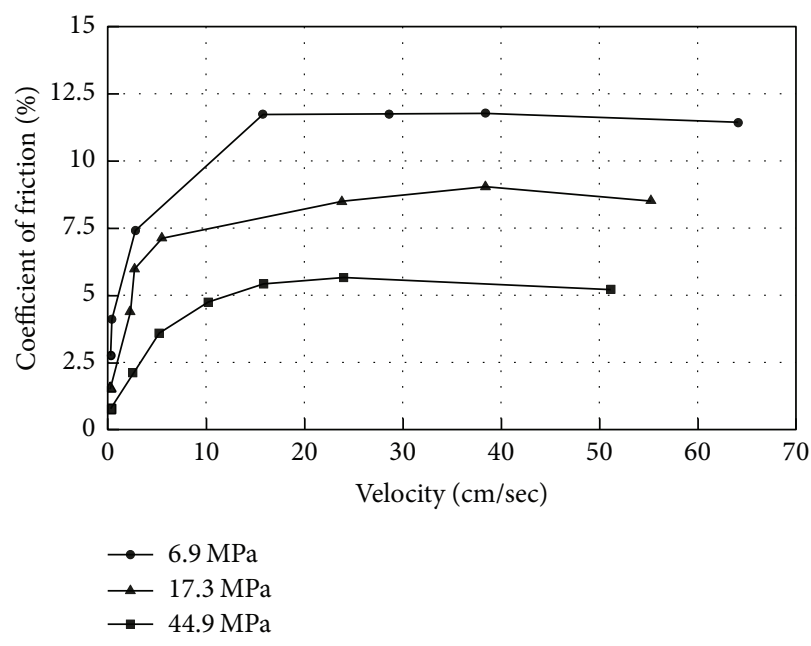

(a)

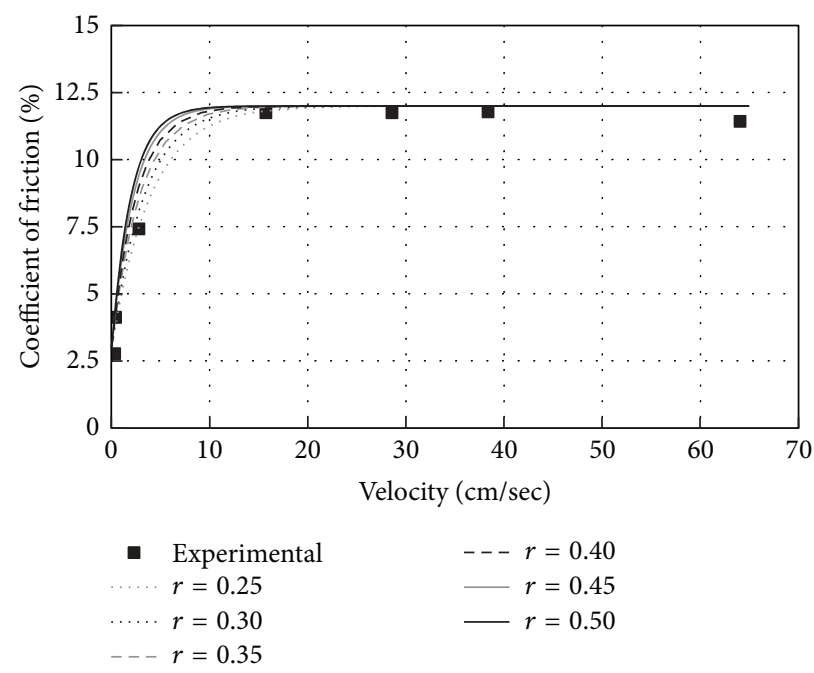

(b)

FIGURE 9: Dependency of the coefficient of friction on sliding velocity: (a) experimental data for different axial stress levels (Mokha et al. 1990); (b) effect of the rate parameter $r$ variation.

Assuming that the higher modes effects on the columns are negligible, bridge structure can be assumed as a SDOF system characterized by a force-displacement diagram similar to that of the FPD isolator. This last condition, which occurs for bridges with stiff substructures when the columns have the same flexibility, was preliminarily verified comparing the final value of the lateral stiffness of the designed isolation system with the corresponding one of the substructure elements [28-47]. Therefore, according to the DDBD principles, for the subsequent evaluation of the radius of curvature value, a trial value of the displacement design for the isolation system $\Delta_{m}$ was considered. This value corresponds to the maximum seismic displacement demand $S_{d}\left(T_{D} ; \xi_{\text {iso }}\right)$ for the site under consideration (referring to an overall system damping value $\left.\xi_{\text {iso }}\right)$ amplified by a safety margin factor $\gamma_{\text {ov }}$ equal to 1.4 (Figure 10(a)). This last choice is due by numerous simplifying assumptions adopted for this phase of dimensioning [14]. The value of $S_{d}\left(T_{D} ; \xi_{\text {iso }}\right)$ was estimated from the elastic displacement response spectrum for periods greater than or equal to $T_{D}$ (corner period). In particular, a trial value of the damping ratio of the isolation system equal to $5 \%$ was assumed in the first step of the design iterative process.

The use of constant displacement spectrum at periods equal to or greater than $2.0 \mathrm{sec}$ is conservative for the bridge site. In fact, according to the relations proposed by Faccioli et al. [48], if the expected earthquake moment magnitude equal to 7 involves a $T_{D}$ value greater than $2 \mathrm{sec}$ the corresponding peak response displacement, due to the epicentral distance (ranged in $60-100 \mathrm{~km}$ ), is less than the value defined by the Code.

It should therefore be ensured, according to capacity design principles, (a) first that the displacement capacity of the isolators is greater than the corresponding seismic demand and, (b) secondly, that the lateral load applied to the existing columns in correspondence of the design displacement $\Delta_{m}$ of FPD isolator induces internal forces at the base cross-section of the column lower than their flexural and shear strengths. Thus, considering that, for structural periods greater than $T_{D}$, the displacement demand is constant and equal to the maximum value, this latter value was assumed as a design parameter.

Starting from the evaluation of the flexural strength $M_{R d}$ value of the cross section at the base of the central column of the pier (equal to $2119 \mathrm{kNm}$ ), the design maximum value of the lateral force $V_{m}$ to consider for a couple of FPD isolators located at the pier top was calculated, also accounting for the second order effects, as follows:

$$
2 V_{m}=\frac{\left(M_{R d}-2 W \Delta_{m}\right)}{h_{P}},
$$

where $W$ is the maximum axial load acting on each device $(996 \mathrm{kN})$ and $h_{P}$ is the pier column height. Therefore, it is possible to calculate the device stiffness $K_{P}$ (Figure 10(b)),

$$
K_{P}=\frac{\left(V_{m}-V_{f}\right)}{\Delta_{m}},
$$

thus, inverting the second relation of (7), to define the design value of the radius of curvature $R_{C}$. According to (11), the equivalent viscous damping of the FPD is mutually related to the design displacement and lateral stiffness (hence radius of curvature) of the isolation systems. Consequently, the curvature radius of the FPD is derived iteratively from the spectrum analyses, changing step-by-step the equivalent viscous damping $\xi_{\text {iso }}$ of the isolation system, having assumed for the FPD isolators, a friction coefficient as a mean value for all the devices over the entire bridge. At the final step of the procedure, an optimal device with $R_{C}$ value of $1.90 \mathrm{~m}$ and $\xi_{\text {iso }}$ value of $32.5 \%$ with a maximum displacement demand equal to $128 \mathrm{~mm}$ was carried out.

The dimensioning of the circular contact section placed between the articulated friction slider and the concave 


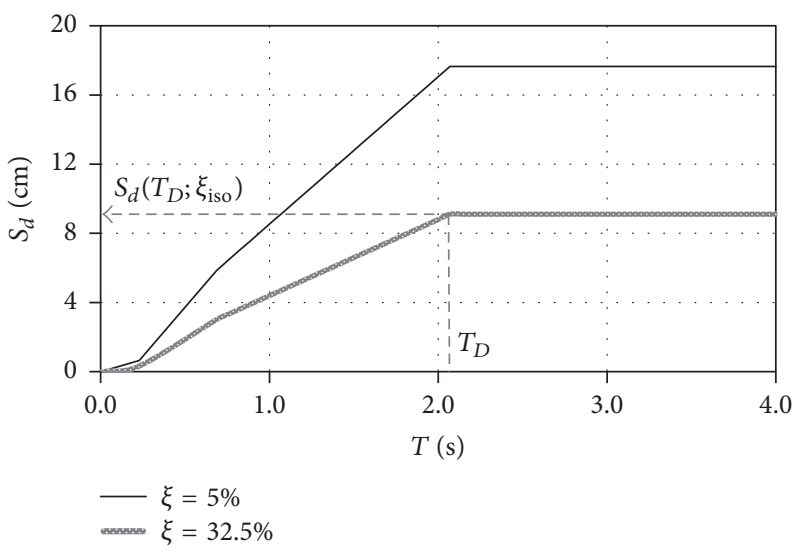

(a)

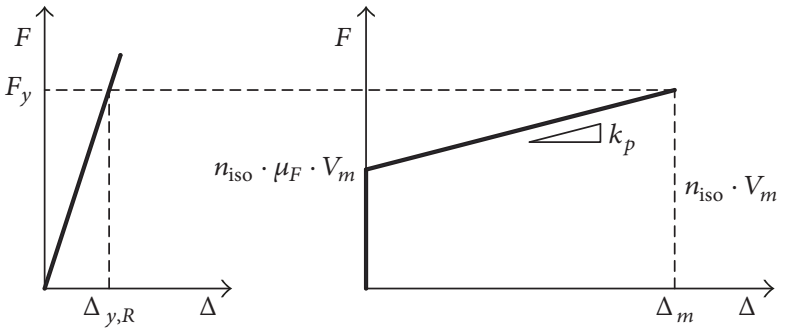

(b)

FIgURE 10: (a) Design displacement spectra; (b) force-displacement diagram of the pier column and of the FPD isolator.

surface of the FPD was also carried out. In particular, considering the maximum axial load $W$ value, introduced above and adopting a maximum value for the contact stress of 44.9 MPa according to the experimental results of Figure 9(a) [40], a minimum radius dimension for the slider $R_{\mathrm{sl}}$ equal to $85 \mathrm{~mm}$ was evaluated. This choice allows achieving the highest value of the friction coefficient at large speeds $\mu_{\text {fast }}$ equal to $6 \%$ and $8 \%$ for internal and external FPD isolators, respectively. Moreover, according to Mokha et al. [40], a value of $2 \%$ was assumed as the friction coefficient at nearly zero velocity $\mu_{\text {slow }}$.

In order to define a more practical consequence of this design process, as a final step, the selection of a FPD isolator among a number of available standard devices, whose characteristics are as much as possible similar to those of the optimal device, was performed. The mechanical properties of both the optimal and standard FPD isolators, as subsequently considered in the analyses, are shown in Table 5. This choice was made in order to compare the results carried out for the seismic response of the isolated bridge adopting the standard device to those obtained considering the FPD optimal solution.

\section{Seismic Bridge Response and Structural Evaluation}

The seismic response assessment of the retrofitted bridge was developed by means of nonlinear response history analysis (NRHA) performed on a structural 3D beam-column frame elements model with FPD isolators, implemented in SAP2000, through a direct integration of the equations of motion technique of the overall isolated system. The geometry and modelling approach of this Seismically Isolated Bridge, where the isolation system is achieved by placing a single FPD concave isolator in correspondence of each original bearing, are illustrated in Figure 11(a). In particular, the superstructure elements are expected to remain within their linear elastic range. Thus, the deck elements (box girder and slab) are modelled using elastic beam column and shell elements. The deck element discretization allows implicitly including the translational and rotational mass of the deck in the model, whereas the FPD isolators are designed to ensure an elastic response for the substructure elements. Therefore the columns of the pier and abutments are modelled using elastic beam-column elements. The nonlinear hysteretic behaviour for the FPD devices was described by a biaxial friction pendulum model depicted in Figure 11(b) (Nonlinear Link named "Friction Isolator"). The model is based on the hysteretic behaviour proposed by Wen [49], Park et al. [50] and recommended for base-isolation analysis by Nagarajaian et al. [51]. The modelling aspects of the FPD device are dealt with, along with the essential physical phenomenon involved in the response. In fact, the influence of the variations in axial load $W$ and friction coefficient $\mu$, in-plane bidirectional sliding interaction, and the orientation of the FPD are taken into account. Rigid elements provide the connection between the FPD device and deck elements (slab and box girders) and columns, respectively. The existing joints placed at the bridge ends must be replaced by new seismic joints with an adequate width so as to avoid the pounding between the deck and abutment wall due to the maximum isolator displacement.

Generally, a bridge structure with an isolation system can be considered as a structural system consisting of a substructure (the columns) and a superstructure (the deck) connected by the seismic isolators. There is a significant difference in damping of the two subsystems and isolation system, which makes the system nonclassically damped. This will lead to the coupling of the motion equations, with an analysis of the system through a complex model analysis being required [52]. Consequently, the damping matrix of the overall seismic isolated bridge can be evaluated through the damping features of each subsystem and then taking into account the effects due to their coupling $[53,54]$. In particular, the complete damping matrix of the seismically isolated bridge $\left[C_{\text {iso }}\right]$ can be expressed as follows:

$$
\left[C_{\mathrm{iso}}\right]=\left[\begin{array}{cc}
{\left[C_{\mathrm{sub}}\right]+\left[C_{o}\right]} & {\left[C_{s p}\right]^{T}} \\
{\left[C_{s p}\right]} & {\left[C_{\mathrm{deck}}\right]}
\end{array}\right] .
$$


TABLE 5: Mechanical properties of FPD optimal and standard isolators.

\begin{tabular}{|c|c|c|c|c|c|c|c|}
\hline Type & Position & $\mu_{\text {slow }}$ & $\mu_{\text {fast }}$ & $R_{C}[\mathrm{~cm}]$ & $\Delta_{m}[\mathrm{~cm}]$ & $\xi_{\mathrm{FP}}\left[\Delta_{m}\right]$ & $T_{P}[\mathrm{~s}]$ \\
\hline \multirow{2}{*}{ Optimal Isolator } & Internal & $2 \%$ & $6 \%$ & 190 & 12.8 & 0.297 & 2.76 \\
\hline & External & $2 \%$ & $8 \%$ & 190 & 12.8 & 0.361 & 2.76 \\
\hline \multirow{2}{*}{ Standard isolator } & Internal & $2 \%$ & $6 \%$ & 250 & 15.0 & 0.341 & 3.17 \\
\hline & External & $2 \%$ & $8 \%$ & 250 & 15.0 & 0.381 & 3.17 \\
\hline
\end{tabular}

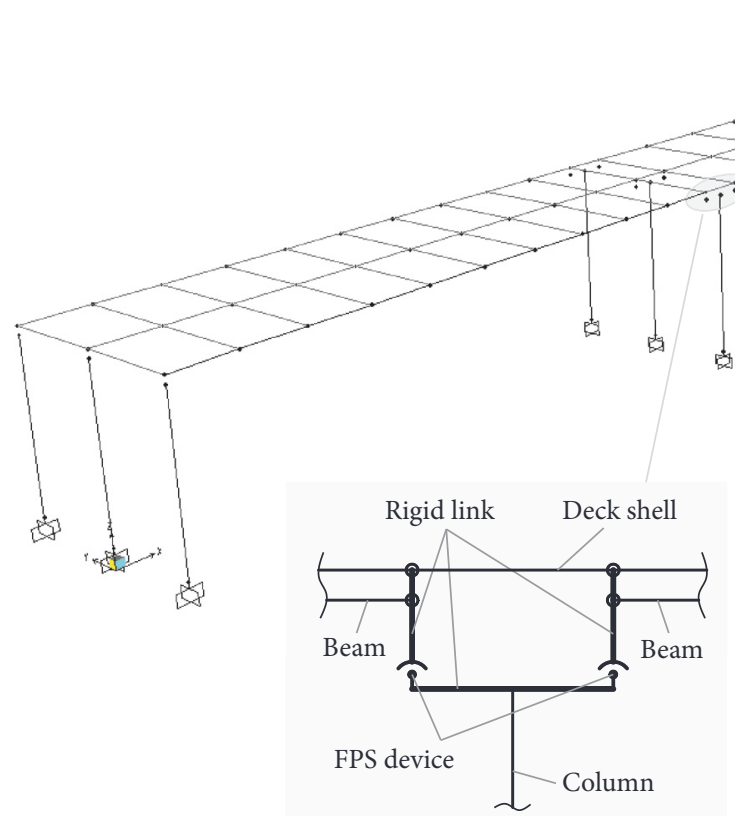

(a)

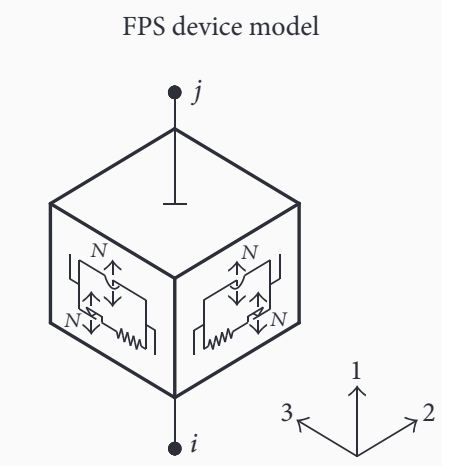

(b)

FIGURE 11: (a) FEM model of the seismic isolated bridge; (b) local modelling of a FPD isolator.

Whereas the superstructure consists of a rigid deck, the related damping matrix $\left[C_{\text {deck }}\right]$ can be directly taken into account by means of the hysteretic response of the FPD isolators. The substructure damping characteristics $\left[C_{\text {sub }}\right]$ can be considered by including in the model viscous dampers placed between the top of the columns (abutments or piers) and a fixed external support along the two main directions $X$ and $Y$. It is well known that different values of the damping can strongly affect the dynamic response [55-59]. Thus, the evaluation of the corresponding damping constants $c_{\mathrm{A} / \mathrm{P}}$ is carried out assuming that the columns behave like SDOF systems along each principal direction:

$$
c_{\mathrm{A} / \mathrm{P}}=2 \xi \sqrt{k_{\mathrm{A} / \mathrm{P}} \cdot M_{\mathrm{A} / \mathrm{P}}},
$$

where $\xi$ is the structural damping ratio of the single column, assumed equal to $3 \%$, while $M_{\mathrm{A} / \mathrm{P}}$ and $k_{\mathrm{A} / \mathrm{P}}$ represent the tributary mass and lateral stiffness of the column (of abutment A or pier $\mathrm{P}$ ) in the considered direction, respectively. Consequently, the eight damping constants reported in Table 6 were calculated, two for each type of column (abutment or pier) depending on the load directions considered (along $X$ and $Y$ ) and on the column position (internal and external). The definition of all these damping characteristics also allows implicitly taking into account the effects of the coupled terms of the complete damping matrix $\left[C_{\text {iso }}\right]$. In particular, the coupling terms consist of the matrix $\left[C_{0}\right]$, that is, the diagonal matrix, representing the increment of dissipation of the substructure elements due to the presence of an isolator device on the top of each column, and the coupling matrix $\left[C_{s p}\right]$ that expresses the coupling between the two substructures.

The seismic response assessment of the isolated bridge was then developed, starting from the outcomes of the NRHA carried out using seven recorded accelerograms of significant historical earthquakes (Table 7). These seismic inputs were selected following the requirement that the spectral displacements in the range 2-6 sec are consistent with the ones of the design displacement spectrum (Figure 12). Their horizontal and vertical components were scaled to a peak ground acceleration values equal to $0.176 \mathrm{~g}$ and $0.054 \mathrm{~g}$, respectively, corresponding to the CP Limit State design as suggested by the code provisions for the site under consideration. The scaling of the signals was done varying only the amplitude and leaving the same frequency content (i.e., the same shape of the response spectrum).

5.1. Effects of the FPD Modelling Parameters. To examine the effects of the modelling parameters for the FPD isolators on 
TABLE 6: Values of the damping constants of the substructure elements.

\begin{tabular}{lcccc}
\hline Direction & $c_{\mathrm{A}, \text { int }}[\mathrm{kN} \cdot \mathrm{s} / \mathrm{m}]$ & $c_{\mathrm{A}, \text { ext }}[\mathrm{kN} \cdot \mathrm{s} / \mathrm{m}]$ & $c_{\mathrm{P}, \text { int }}[\mathrm{kN} \cdot \mathrm{s} / \mathrm{m}]$ & 223.68 \\
\hline Longitudinal $X$ & 215.94 & 179.95 & $c_{\mathrm{P}, \text { ext }}[\mathrm{kN} \cdot \mathrm{s} / \mathrm{m}]$ \\
Transverse $Y$ & 120.84 & 100.70 & 125.22 & 186.40 \\
\hline
\end{tabular}

TABLE 7: Earthquake ground motion parameters.

\begin{tabular}{|c|c|c|c|c|c|c|c|c|c|}
\hline \multirow{2}{*}{ Number } & \multirow{2}{*}{ Earthquake record } & \multirow{2}{*}{ Id. station } & \multirow{2}{*}{ Date } & \multicolumn{3}{|c|}{ Component PGA [g] } & \multirow{2}{*}{$M_{w}$} & \multirow{2}{*}{$T_{R}[\mathrm{~s}]$} & \multirow{2}{*}{$I_{A}[\mathrm{~m} / \mathrm{s}$} \\
\hline & & & & Long. & Trans. & Vert. & & & \\
\hline (1) & Christchurch & RHSC & $21 / 02 / 11$ & 0.290 & 0.250 & 0.195 & 57 & 57 & 1.115 \\
\hline (2) & Off Noto P. & ISK006 & $25 / 03 / 07$ & 0.866 & 0.732 & 0.462 & 75 & 75 & 9.061 \\
\hline (3) & South Iceland & 306 & $21 / 06 / 00$ & 0.109 & 0.091 & 0.063 & 40 & 40 & 0.067 \\
\hline (4) & Kagoshima & KGS004 & $26 / 03 / 97$ & 0.134 & 0.299 & 0.098 & 70 & 70 & 1.011 \\
\hline (5) & Northridge & 24087 & $17 / 01 / 94$ & 0.344 & 0.308 & 0.552 & 60 & 60 & 1.469 \\
\hline (6) & Loma Prieta & 57007 & $18 / 10 / 89$ & 0.479 & 0.630 & 0.439 & 40 & 40 & 3.175 \\
\hline$(7)$ & Irpinia & Calitri & $23 / 11 / 80$ & 0.175 & 0.158 & 0.166 & 86 & 86 & 1.364 \\
\hline
\end{tabular}

TABLE 8: Summary of seismic isolated bridge model parameters.

\begin{tabular}{|c|c|c|c|}
\hline Model & Vertical component & Coefficient of friction variability & Rate coefficient $[\mathrm{s} / \mathrm{m}]$ \\
\hline \multicolumn{4}{|c|}{ ( } \\
\hline$(2)^{\mathrm{a}}$ & • & & \\
\hline$(3)^{b}$ & • & • & 30 \\
\hline$(4)^{\mathrm{b}}$ & • & - & 20 \\
\hline$(5)^{b}$ & • & • & 50 \\
\hline
\end{tabular}

${ }^{\mathrm{a}} \mu_{\text {slow }}=\mu_{\text {fast }}=3 \%{ }^{\mathrm{b}} \mu_{\text {slow }}=2 \% \mu_{\text {fast,int }}=6 \% \mu_{\text {fast }, \text { ext }}=8 \%$.

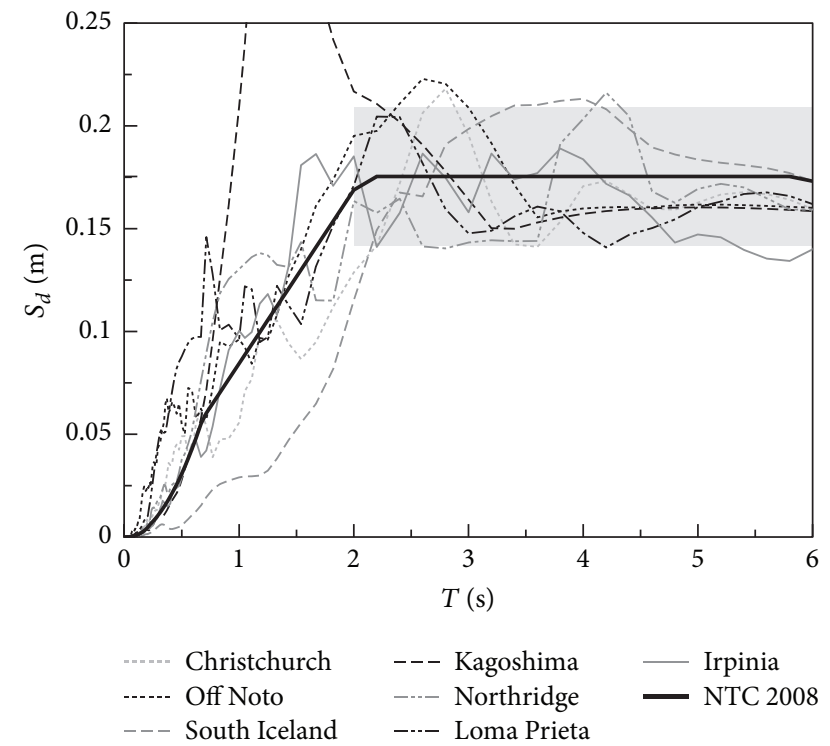

FIGURE 12: Ground motion displacement response spectra comparing with the Italian Code (NTC2008) elastic response spectrum.

the seismic response of the retrofitted bridge, the five seismic isolated bridges models indicated in Table 8 are considered. All the models account for the bidirectional coupling of the sliding forces, incorporating the $P-\Delta$ moments and considering the friction coefficient at low sliding velocity $\mu_{\text {slow }}$ equal to 0.02 . The comparison between the seismic performances of the retrofitted bridge isolated by means of the optimal and standard FPD isolators were also carried out.

The effects of the modelling parameters on the seismic response of the retrofitted bridge were evaluated through the results of nonlinear response history analyses (NRHA) carried out using the recorded accelerogram of Irpinia. These results, expressed in terms of the maximum value of the lateral displacement and axial force of the isolators placed at the top of the pier external columns and bending moment about a weak axis and shear in the transverse direction for the cross section at the base of the corresponding column, are compared in Table 9.

In particular, in model 1 , the value of axial force on the FPD is taken as the corresponding constant value after the gravity load analysis and includes the effect of the horizontal components of the earthquake ground motion, while, in model 2, the effect of the vertical component is explicitly taken into account. In particular, for these two models, a constant value of the friction coefficient at slow and large sliding velocity equal to 0.03 for the devices is assumed. The comparison between the results, carried out through models 1 and 2, shows how the vertical component of the earthquake ground motion has a negligible effect on the lateral displacement peak value of the FPD seismic isolators as well as on the bending moment and shear at base of 


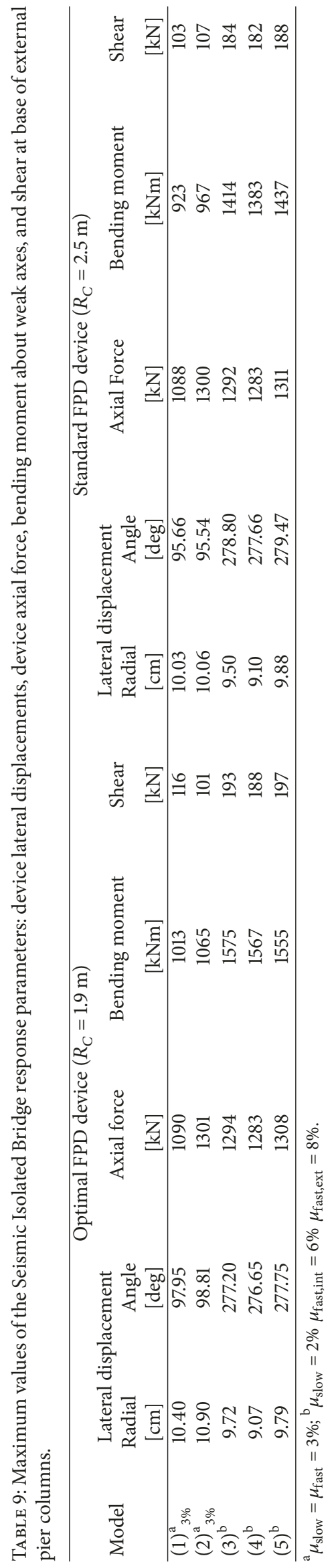


the external pier column. On the other hand, this vertical component of the seismic action leads to an increase of the peak value of the device axial force equal to $19 \%$.

Model 3 is developed in order to evaluate the effect of the friction coefficient variation considering the rule of (12). In particular, a value of the friction coefficient at low sliding velocity $\mu_{\text {slow }}$ equal to 0.02 and a maximum value of the friction coefficient at large sliding velocity $\mu_{\text {fast }}$ equal to 0.06 and 0.08 for internal and external devices, respectively, with a rate parameter $r$ value equal to 30 were assumed. The comparison between the results carried out through models 2 and 3, with the use of an optimal FPD device, shows how the effect of friction coefficient variation leads to a slight variation in the lateral displacement peak value equal to $10.8 \%$, whereas there is a notable increase in the peak value of the bending moment and shear, respectively, equal to $47.9 \%$ and $91.1 \%$. The effect of the friction coefficient variability was found with a similar trend for the response parameters of the substructure element of the seismic isolated bridge with the use of a standard FPD device, whereas the effects in terms of maximum device displacement are negligible.

Moreover, the effect of the rate parameter was evaluated comparing the results carried out with model 3 as well as those obtained with models 4 and 5 , for which two extreme values of the rate parameter, respectively, equal to 20 and 50 were considered. In fact, a typical value for this parameter ranged between 20 and $30 \mathrm{~s} / \mathrm{cm}$ for unfilled PTFE and up to $50 \mathrm{~s} / \mathrm{cm}$ for composite PTFE [22]. This comparison shows how the effect of the rate parameter variation is negligible on the seismic response of the seismic isolated bridge for all the devices used.

As a result of all the comparison and sensitivity analyses, it follows that the vertical component of the earthquake ground motion and the variability of the friction coefficient should be taken into account in order to carry out an accurate seismic response assessment of the seismic isolated bridge with FPD isolators, while the rate parameter has only a slight and negligible impact on the response parameters. In particular, the effect of the axial load variability in the FPD isolator has been duly taken into account for the selection of the device bearing capacity and the relating value of the friction coefficient at a high sliding velocity $\mu_{\text {fast }}$.

5.2. Structural Evaluation of Retrofitting Bridge. The seismic response assessment of the Seismically Isolated Bridge and the verification of the preliminary seismic design process were finally performed using model 3 that considers the effect of the vertical component of earthquake ground motion, the variability of the coefficient of friction (between 0.02 and 0.06 for the devices placed on internal columns and between 0.02 and 0.08 for the devices placed on the external ones), adopting a value for the rate parameter equal to 30 . In particular, the verification was carried out for the seismic isolated bridge where the optimal FPD isolators were used. The seismic isolated bridge model was analysed for gravity load and sequentially subjected to NRHA analyses using simultaneously the longitudinal, transverse, and vertical acceleration records of the given earthquake. In particular, the in-plane orthogonal components of the earthquake were oriented along the transverse direction $(Y)$ to result in the maximum demands on the columns.

With reference to the FPD devices, the safety checks, developed by comparing the lateral displacement demand with the corresponding displacement capacity $\left(\Delta_{m}\right.$ equal to $12.8 \mathrm{~cm}$ ), are always fulfilled. In particular, the seismic response of the isolators placed at the top of the external columns of the piers and of the internal column of the abutments, in terms of lateral displacement along the two main directions $X$ and $Y$, are shown in Figures 13 and 14. The fulfilment of these safety checks highlights that the energy dissipation capacity of the FPD devices is sufficient to limit the seismic displacement demand and replace the need for additional energy dissipation devices. The time history hysteresis loops for the FPD isolators, placed at the top of the pier columns and of the abutment columns, as an effect of the Irpinia earthquake along the transverse direction, are in good agreement with the theoretical ones constructed on the basis of (7) and (10) using, respectively, $\mu_{\text {fast }}$ values equal to 0.08 and 0.06 for the friction coefficient at a high velocity (Figure 15).

The other safety checks were performed taking into account the maximum values of the internal forces calculated by means of the NRHA. In particular, in Figure 16, the intersection domain between the conventional failure interaction surface of the axial force and the biaxial bending moments $P-M_{x}-M_{y}$ with the plan of equation $P=$ cost for the crosssection at the base of the central columns of pier and external columns of the abutment are represented. The checkpoints refer to the maximum bending moment value calculated for each main direction and the corresponding value in orthogonal direction using all the sets of signals selected.

The safety checks are widely fulfilled, providing very satisfactory confirmation of the reliability of the adopted seismic retrofit intervention. In fact, the seismic isolation strategy, giving high lateral deformation to the bridge superstructure, permits reducing significantly the internal force levels in the columns, allowing them to remain within linear elastic range to the new seismic design forces for the CP Limit State defined for the site under consideration.

\section{Conclusions}

The paper deals with the proposal and application of a procedure for the seismic retrofit of an existing multispan prestressed concrete girder bridge, whose structural scheme is representative of a fairly widespread typology for the construction of road bridges.

The procedure is based on three steps that specifically concern (a) the seismic risk assessment of the existing bridge; (b) the design process of a bridge retrofit intervention based on the seismic isolation of the deck with friction pendulum devices (FPD); (c) the seismic response assessment of the seismically isolated bridge and the evaluation of the performance level achieved after the seismic retrofit intervention.

Starting from the knowledge of the geometry and material properties derived by the original drawings and design report, the seismic risk assessment of the existing bridge towards the new seismic actions, provided by the current Italian Code provisions, was performed. With this 

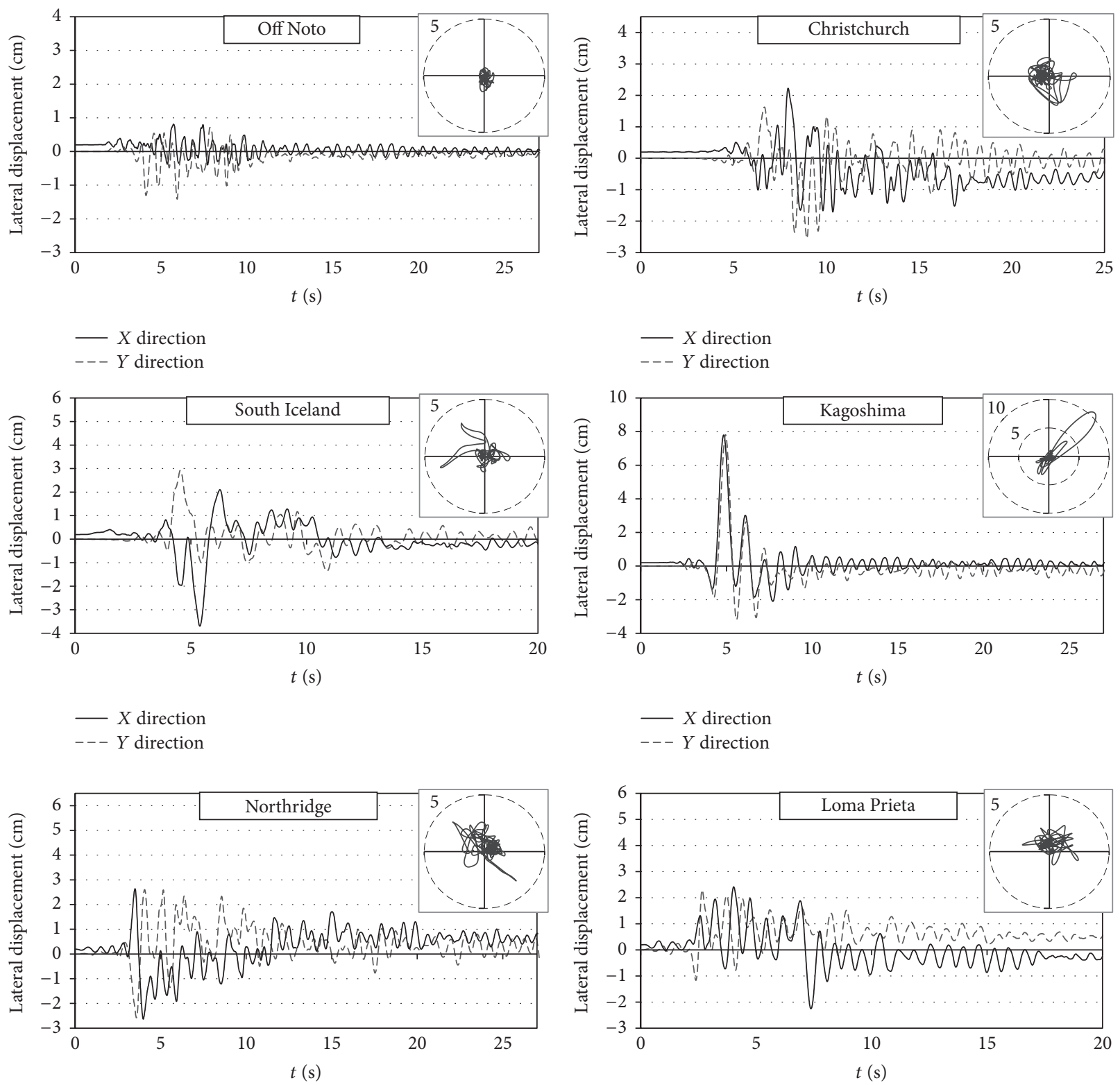

$X$ direction

$X$ direction

-- $Y$ direction

--- $Y$ direction
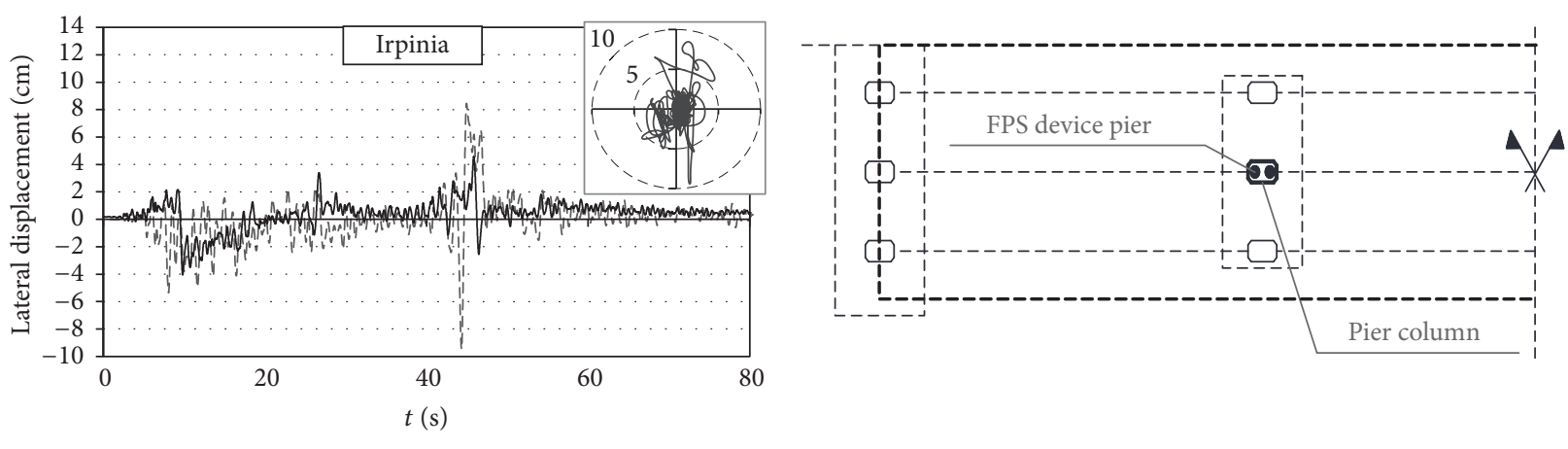

$-X$ direction

--- $Y$ direction

FIGURE 13: Seismic response of the FPD isolators placed at the top of pier internal column for earthquake along the transverse direction. 

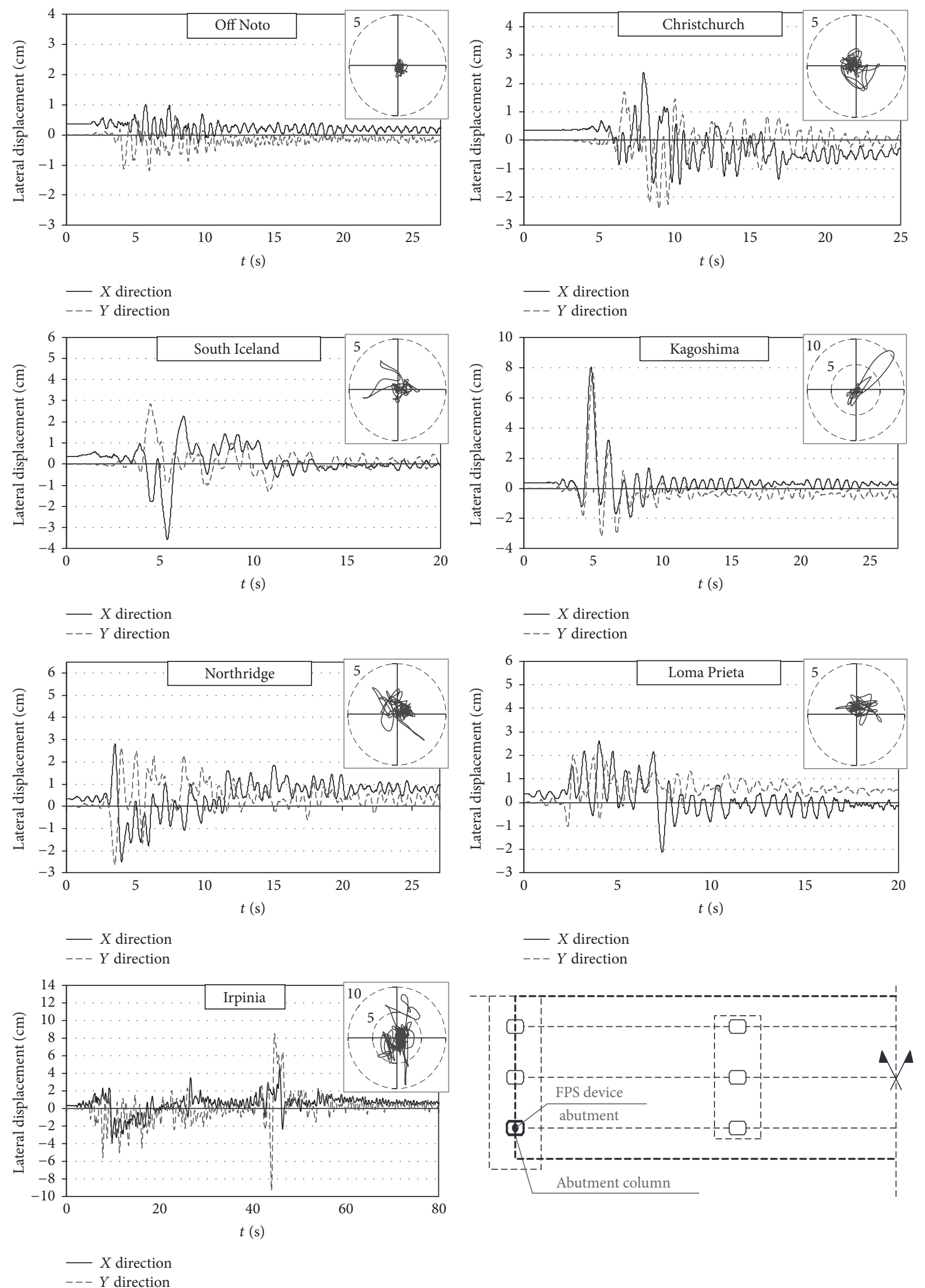

FIGURE 14: Seismic response of the FPD isolators placed at the top of abutment external column for earthquake along the transverse direction. 

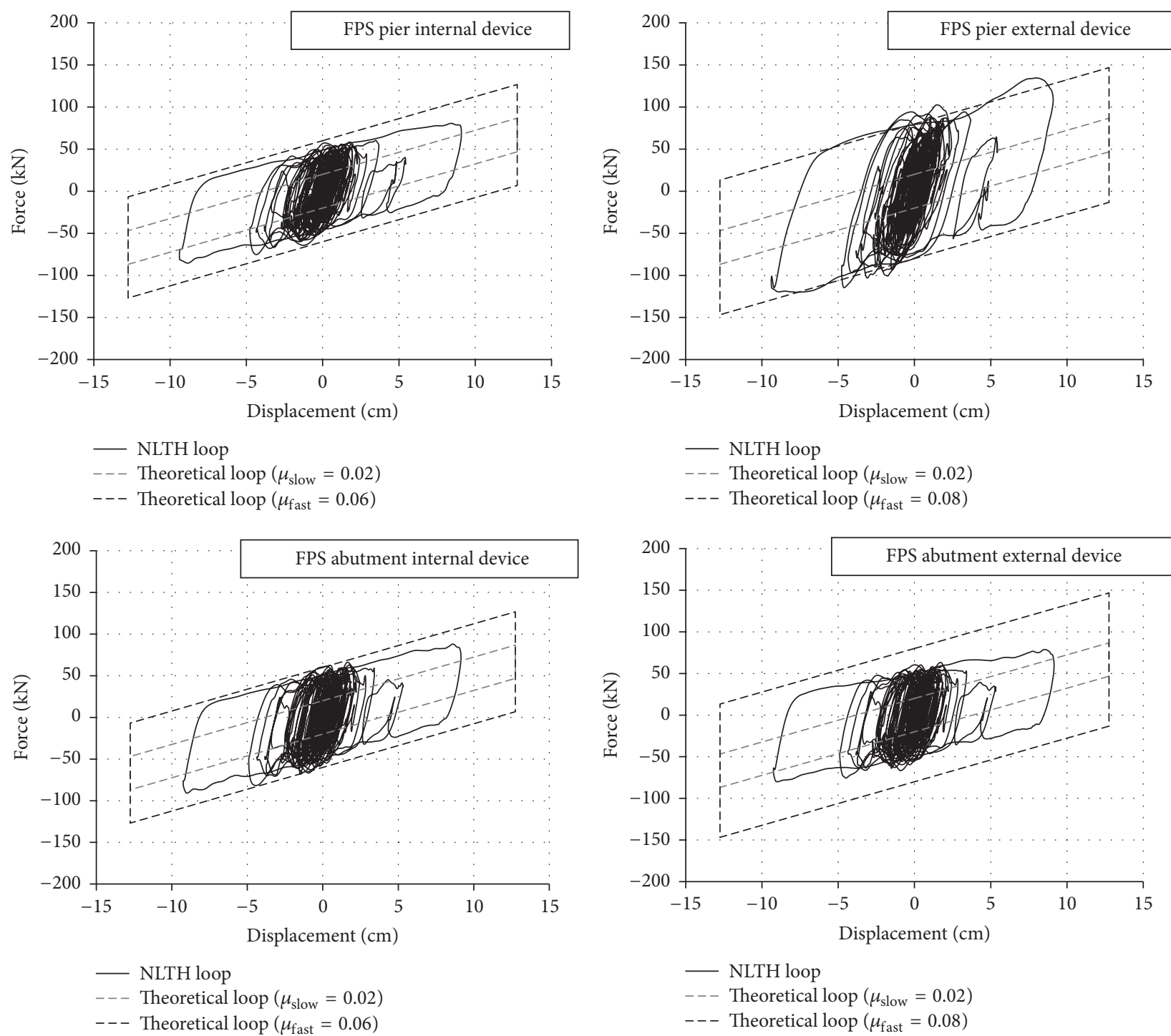

FIGURE 15: Comparison between theoretical and time history hysteresis loops, as effect of Irpinia earthquake along the transverse direction, for the FPD isolators placed at the top of pier columns and abutment columns.

aim, an incremental noniterative Nonlinear Static Procedure (NSP) inspired to the Pushover analysis, Capacity Spectrum Method, and Inelastic Demand Response Spectra was applied. The use of this NSP permitted carrying out, according to the Performance-Based Earthquake Engineering, the values of PGA for which the structural capacity meets the seismic demand for the Limit State taken into account and, consequently, calculating the corresponding risk index. The results point out the inadequate lateral displacement capacity as well as the limited global ductility of the existing bridge towards the new "seismic demand" levels provided by the current seismic code.

Consequently, the second step concerns the design of a seismic retrofit intervention based on the deck isolation by using friction pendulum devices, FPD. In particular, the dimensioning of the isolation devices was developed through a multiobjective approach in order to meet the performance levels provided for different operating conditions of the bridge. The first design objective was to avoid the lateral displacement of the deck under the lateral actions due to wind loads and braking forces defined according to the Serviceability Limit State SLS level. The second design objective was to ensure that the seismic response of the columns remained within their linear elastic range when the deck reached the maximum lateral displacement demand provided by the seismic code for the Ultimate Limit State SLU level.

The paper also examined, for this specific case, the effects of the FPD modelling parameters on the seismic response of the retrofitted bridge through nonlinear response history analyses involving a solution of the complete set of equilibrium equations at each time increment. In particular, the sensitivity analyses have shown how the vertical component of the earthquake ground motion and the variability of the coefficient of friction of the FPD isolator should be taken into 

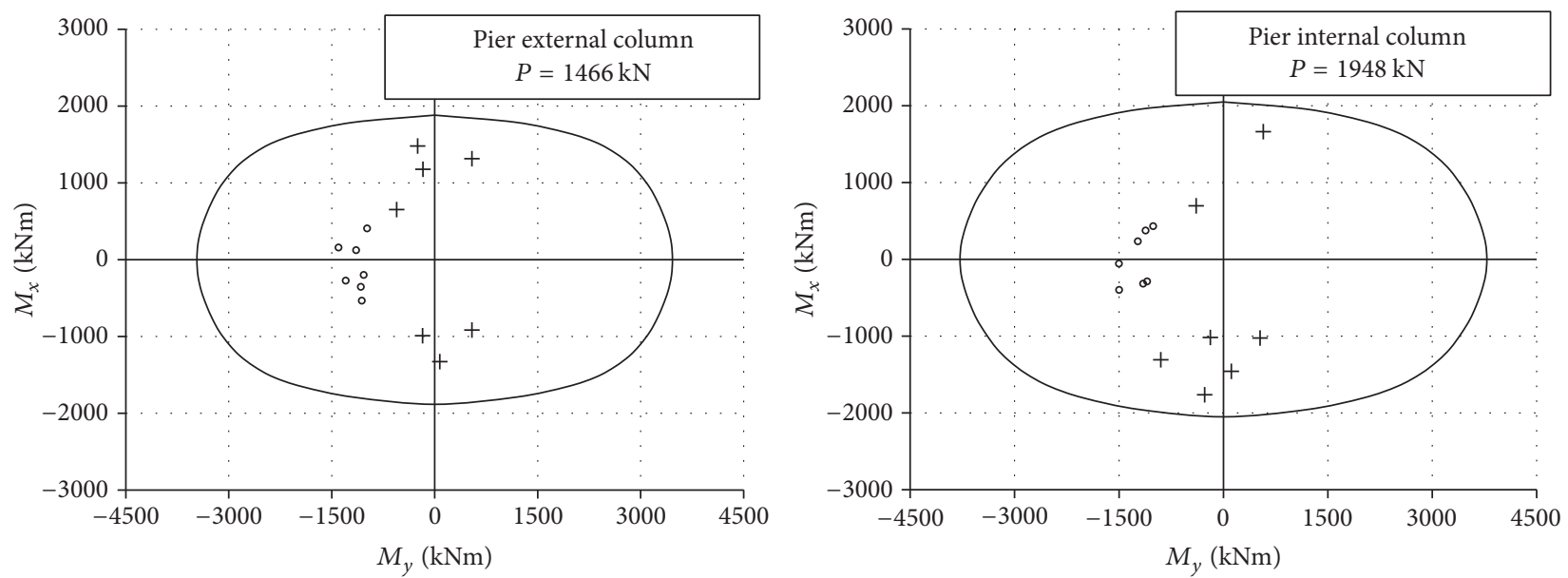

$+M x, \max ; M y$

- $M y, \max ; M x$

$+M x, \max ; M y$

- $M y, \max ; M x$
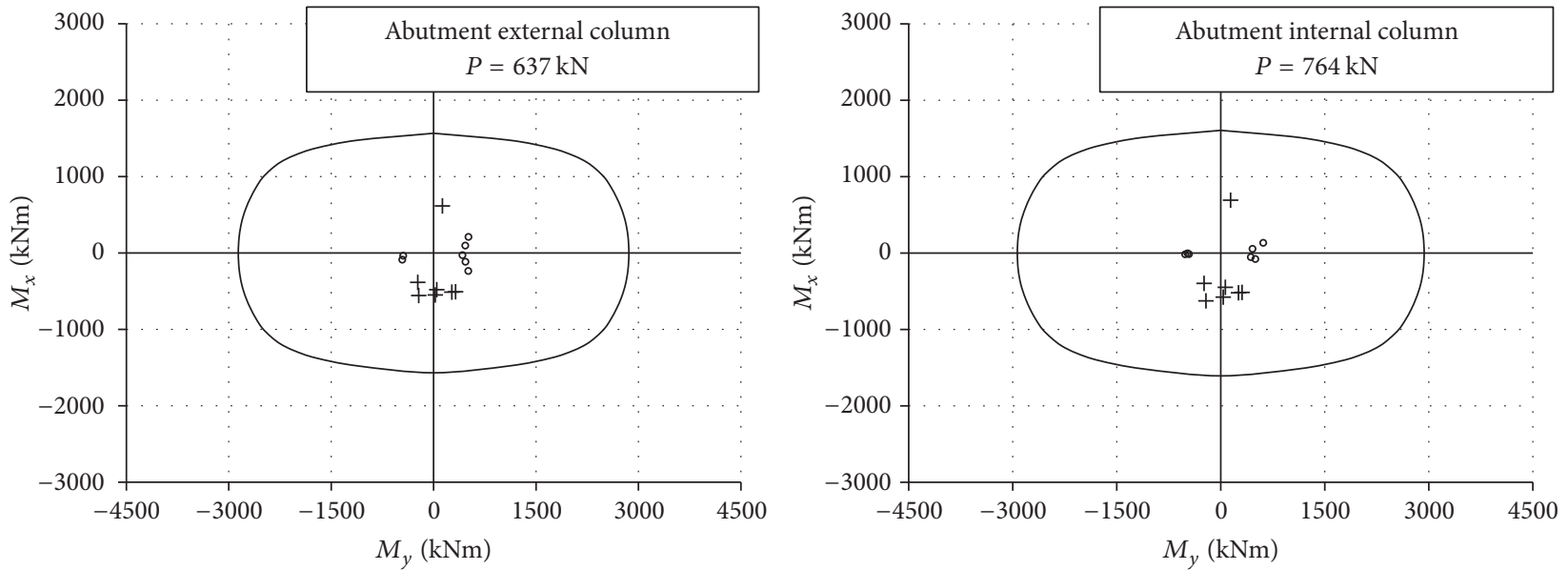

$+M x, \max ; M y$

- $M y, \max ; M x$

$+M x, \max ; M y$

- $M y, \max ; M x$

Column

cross section

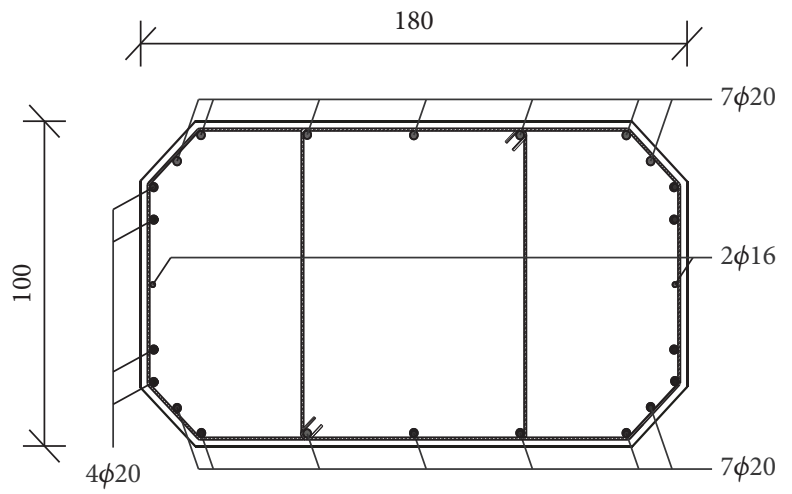

FIGURE 16: Safety check of the cross section at the base of internal and external columns of piers and abutments.

account in order to carry out an accurate seismic response assessment of a seismically isolated bridge. On the other hand, the rate parameter has shown only a slight impact on the structural response parameters. In particular, the effect of the axial load variability in the FPD isolator was relevant for the selection of the device bearing capacity and the relative value of the friction coefficient at a high sliding velocity $\mu_{\text {fast }}$, while the effect of the variability of the coefficient of friction 
of the FPD isolator allowed better estimation of the seismic demand to the substructure elements.

Finally, the last step of the procedure consists in the seismic response assessment of the seismically isolated bridge, evaluated through nonlinear response history analyses, also taking into account a complete damping matrix definition. The outcomes point out the efficiency of the bridge retrofit intervention. In fact, a meaningful decrease of the internal forces in the columns was found, permitting these substructure elements to resist within their elastic range to the seismic actions defined for the CP Limit State at the site under consideration. Moreover, the use of these isolation devices replaced the need for additional energy dissipation devices. In conclusion, the use of FPD as seismic retrofit strategy, in this case, effectively mitigated the seismic forces and eliminated the need for costly retrofitting of the bridge substructure components.

\section{Conflicts of Interest}

The authors declare that there are no conflicts of interest regarding the publication of this paper.

\section{References}

[1] CEN, Design of Structures for Earthquake Resistance, Part 1: general rules, seismic actions and rules for buildings, EN1998-1, European Committee for Standardization, 2004.

[2] D.M. 14.01.2008, Italian Code (2008). Norme tecniche per le costruzioni in zone sismiche. Ministerial Decree, G.U. No. 9 04.02.08 (in Italian).

[3] M. C. Constantinou, A. Kartoum, A. M. Reinhorn, and P. Bradford, "Sliding isolation system for bridges: experimental study," Earthquake Spectra, vol. 8, pp. 321-344, 1992.

[4] A. Kartoum, M. C. Constantinou, and A. M. Reinhorn, "Sliding isolation system for bridges: Analytical study," Earthquake Spectra, vol. 8, pp. 345-372, 1992.

[5] P. Tsopelas, M. C. Constantinou, S. Okamoto, S. Fujii, and D. Ozaki, "Experimental study of bridge seismic sliding isolation systems," Engineering Structures, vol. 18, no. 4, pp. 301-310, 1996.

[6] Y. P. Wang, L. L. Chung, and W. H. Liao, "Seismic response analysis of bridges isolated with friction pendulum bearings," Earthquake Engineering \& Structural Dynamics, vol. 27, pp. 10691093, 1998.

[7] M. Dicleli and M. Y. Mansour, "Seismic retrofitting of bridges in Illinois using friction pendulum seismic isolation bearings and modeling procedures," Engineering Structures, vol. 25, pp. 1139-1156, 2003.

[8] W. I. Liao, C. H. Loh, and B. H. Lee, "Comparison of dynamic response of isolated and non-isolated continuous girder bridges subjected to near-fault ground motions," Engineering Structures, vol. 26, no. 14, pp. 2173-2183, 2004, http://dx.doi.org/10.1016/j .engstruct.2004.07.016.

[9] S. Ates, A. A. Dumanoglu, and A. Bayraktar, "Stochastic response of seismically isolated highway bridges with friction pendulum systems to spatially varying earthquake ground motions," Engineering Structures, vol. 27, no. 13, pp. 1843-1858, 2005.

[10] M. Dicleli and S. Buddaram, "Effect of isolator and ground motion characteristics on the performance of seismic-isolated bridges," Earthquake Engineering \& Structural Dynamics, vol. 35, no. 2, pp. 233-250, 2006.

[11] R. S. Jangid, "Stochastic response of bridges seismically isolated by friction pendulum system," Journal of Bridge Engineering, vol. 13, no. 4, pp. 319-330, 2008.

[12] R. D. Bertero and V. V. Bertero, "Performance-based seismic engineering: the need for a reliable conceptual comprehensive approach," Earthquake Engineering \& Structural Dynamics, vol. 31, no. 3, pp. 627-652, 2002.

[13] M. J. N. Priestley, "Performance based seismic design," Bulletin of the New Zealand Society for Earthquake Engineering, vol. 33, no. 3, pp. 325-346, 2000.

[14] M. J. N. Priestley, G. M. Calvi, and M. J. Kowalsky, DisplacementBased Seismic Design of Structures, IUSS Press, Pavia, Italy, 2007.

[15] G. M. Calvi and A. Pavese, "Conceptual design of isolation systems for bridge structures," Journal of Earthquake Engineering, vol. 1, pp. 193-218, 1997.

[16] M. Jara and J. R. Casas, "A direct displacement-based method for the seismic design of bridges on bi-linear isolation devices," Engineering structures, vol. 28, no. 6, pp. 869-879, 2006, http:// dx.doi.org/10.1016/, j.engstruct.2005.10.016.

[17] D. Cardone, M. Dolce, and G. Palermo, "Direct displacementbased design of seismically isolated bridges," Bulletin of Earthquake Engineering, vol. 7, no. 2, pp. 391-410, 2008.

[18] D. Pietra, G. M. Calvi, and R. Pinho, Displacement-Based Seismic Design of Isolated Bridges, (Research Report Rose 2008/01), IUSS Press, Pavia, Italy, 2008.

[19] A. M. Avossa and P. Malangone, "Seismic Retrofit of a Prestressed Concrete Road Bridge," Ingegneria Sismica (International Journal of Earthquake Engineering), vol. 4, pp. 5-15, 2012, http://ingegneriasismica.org/it/2012/12/.

[20] A. M. Avossa, R. Di Camillo, and P. Malangone, "Performancebased retrofit of a prestressed concrete road bridge in seismic area," in Proceedings of the 3rd Int. Symp. on Life-Cycle Civil Engineering, pp. 1905-1913, Vienna, Austria, 2012.

[21] P. Fajfar, "Capacity spectrum method based on inelastic demand spectra," Earthquake Engineering \& Structural Dynamics, vol. 28, no. 9, pp. 979-993, 1999.

[22] M. Eröz and R. DesRoches, "Bridge seismic response as a function of the Friction Pendulum System (FPD) modelling assumption," Engineering Structures, vol. 30, pp. 3204-3212, 2008.

[23] M. C. Constantinou, A. Mokha, and A. Reinhorn, "Teflon bearings in base isolation. II: Modeling," Journal of Structural Engineering, vol. 116, no. 2, pp. 455-474, 1990.

[24] D.M. 16.01.1996, Italian Code (1996). Norme tecniche per le costruzioni in zone sismiche. Ministerial Decree, G.U. No. 29 - 05.02.96 (in Italian).

[25] ASTM A36/A36M-14 (2014), Standard Specification for Carbon Structural Steel, ASTM International, West Conshohocken, PA, www.astm.org.

[26] J. B. Mander, M. J. N. Priestley, and R. Park, "Theoretical stressstrain model for confined concrete," Journal of Structural Engineering, vol. 114, no. 8, pp. 1804-1826, 1988.

[27] M. Saatcioglu and S. R. Razvi, "Strength and ductility of confined concrete," Journal of Structural Engineering, vol. 118, no. 6, pp. 1590-1607, 1992.

[28] AASHTO, Guide Specifications for Seismic Isolation Design, American Associations of State Highway and Transportation Officials, Wash, DC, USA, 1999. 
[29] Y. Zheng, T. Usami, and H. Ge, "Seismic response predictions of multi-span steel bridges through pushover analysis," Earthquake Engineering and Structural Dynamics, vol. 27, pp. 397-412, 2003.

[30] T. Vidic, P. Fajfar, and M. Fischinger, "Consistent inelastic design spectra: strength and displacement," Earthquake Engineering \& Structural Dynamics, vol. 23, no. 5, pp. 507-521, 1994.

[31] M. Ferraioli, A. M. Avossa, and F. Formato, "Base isolation seismic retrofit of a hospital building in Italy: design and construction," in Proceedings of the Final Conference on COST Action C26: Urban Habitat Constructions under Catastrophic Events, pp. 835-840, September 2010.

[32] V. A. Zayas, S. S. Low, and S. A. Mahin, The FPD earthquake resisting system: experimental report, Earthquake Engineering Research Center, University of California, Berkeley, 1987.

[33] Earthquake Protection Systems, "Technical Characteristics of Friction Pendulum Bearings," Tech. Rep., Vallejo, California, 2003.

[34] F. Naeim and J. Kelly, Design of seismic isolated structures, Wiley, New York, NY, USA, 1996.

[35] M. Dolce, D. Cardone, and F. Croatto, "Frictional behavior of steel-PTFE interfaces for seismic isolation," Bulletin of Earthquake Engineering, vol. 3, no. 1, pp. 75-99, 2005.

[36] G. Mosqueda, A. S. Whittaker, and G. L. Fenves, "Characterization and modeling of friction pendulum bearings subjected to multiple components of excitation," Journal of Structural Engineering, vol. 130, no. 3, pp. 433-442, 2004, http://dx.doi.org/10 $.1061 /$.

[37] Y. Takahashi, H. Iemura, S. Yanagawa, and M. Hibi, "Shaking table test for frictional isolated bridges and tribological numerical model of frictional isolator," in Proceedings of the Proc. of 13th World Conf. on Earthquake Engineering, Vancouver, Canada, 2004, paper n.1531.

[38] M. Dicleli, "Seismic design of lifeline bridge using hybrid seismic isolation," Journal of Bridge Engineering, vol. 7, no. 2, pp. 94-103, 2002.

[39] R. S. Jangid, "Optimum friction pendulum system for nearfault motions," Engineering Structures, vol. 27, no. 3, pp. 349-359, 2005.

[40] A. Mokha, M. C. Constantinou, and A. Reinhorn, "Teflon bearings in base isolation I: testing," Journal of Structural Engineering, vol. 116, no. 2, pp. 438-454, 1990.

[41] M. C. Constantinou, A. Kartoum, A. M. Reinhorn, and P. Bradford, "Experimental and theoretical study of a sliding isolation system for bridges," Tech. Rep., State University of New York at Buffalo, 1991.

[42] P. Tsopelas, M. C. Constantinou, Y. S. Kim, and S. Okamoto, "Experimental study of FPD system in bridge seismic isolation," Earthquake Engineering and Structural Dynamics, vol. 25, pp. 65-78, 1996.

[43] M. C. Constantinou, P. Tsopelas, Y. S. Kim, and S. Okamoto, "NCEER-Taisei corporation research program on sliding seismic isolation system for bridges: Experimental and analytical study of a frictional pendulum system (FPD)," Tech. Rep. NCEER-93-0020, Buffalo, New York, NY, USA, 1993.

[44] P. W. Warn and A. S. Whittaker, "Performance estimates in seismically isolated bridge structures," Engineering Structures, vol. 26, no. 9, pp. 1261-1278, 2004.

[45] J. Almazan and J. De la Llera, "Physical model for dynamic analysis of structures with FPD isolators," Earthquake Engineering and Structural Dynamics, vol. 32, pp. 1157-1184, 2003.
[46] J. M. Kelly, Theory and practice of seismic-isolation design, Earthquake Engineering Research Center, University of California at Berkeley, 1992.

[47] AASHTO, LRFD Bridge Design Specifications, American Associations of State Highway and Transportation Officials, Wash, DC, USA, 2nd edition, 1998.

[48] E. Faccioli, R. Paolucci, and J. Rey, "Displacement Spectra for Long Periods," Earthquake Spectra, vol. 20, no. 2, pp. 347-376, 2004, http://dx.doi.org/10.1193/1.1707022.doi.

[49] Y. K. Wen, "Method for Random Vibration of Hysteretic Systems," Journal of the Engineering Mechanics Division, vol. 102, No. EM2, pp. 224-263, 1976.

[50] Y. J. Park, Y. K. Wen, and A. H.-S. Ang, "Random vibration of hysteretic systems under bi-directional ground motions," Earthquake Engineering \& Structural Dynamics, vol. 14, no. 4, pp. 543-557, 1986.

[51] S. Nagarajaian, A. M. Reinhorn, and M. C. Constantinou, "Nonliner Dynamic Analysis of 3-D Base-Isolated Structures," Journal of Structural Engineering, vol. 117, no. 7, pp. 2035-2054, 1991, http://dx.doi.org/10.1061/.

[52] H. C. Tsai and J. M. Kelly, "Seismic response of heavily damped base isolated buildings," Earthquake Engineering and Structural Dynamics, vol. 22, pp. 633-645, 1993.

[53] P. Malangone and M. Ferraioli, "A modal procedure for seismic analysis of non-linear base-isolated multistorey structures," Earthquake Engineering \& Structural Dynamics, vol. 27, no. 4, pp. 397-412, 1998.

[54] A. M. Avossa and G. Pianese, "Damping effects on the seismic response of base-isolated structures with LRB devices," Ingegneria Sismica (International Journal of Earthquake Engineering), vol. 2, pp. 3-30, 2017, http://ingegneriasismica.org/it/2017/06/.

[55] A. K. Chopra, Dynamics of Structures: Theory and Applications to Earthquake Engineering, Pearson Prentice Hall, 2017.

[56] A. M. Avossa, C. Demartino, and F. Ricciardelli, "Design procedures for footbridges subjected to walking loads: comparison and remarks," The Baltic Journal of Road and Bridge Engineering, vol. 12, no. 2, pp. 94-105, 2017.

[57] C. Demartino, A. M. Avossa, and F. Ricciardelli, "Deterministic and Probabilistic Serviceability Assessment of Footbridge Vibrations due to a Single Walker Crossing," Shock and Vibration, Hindawi, 26 pages, 2018, https://doi.org/10.1155/2018/ 1917629.

[58] F. Ricciardelli and C. Demartino, "Design of footbridges against pedestrian-induced vibrations," Journal of Bridge Engineering, vol. 21, no. 8, Article ID C4015003, pp. 1-13, 2016.

[59] A. M. Avossa, C. Demartino, and F. Ricciardelli, "Probability distribution of footbridge peak acceleration to single and multiple crossing walkers," Procedia Engineering, vol. 199, pp. 27662771, 2017. 


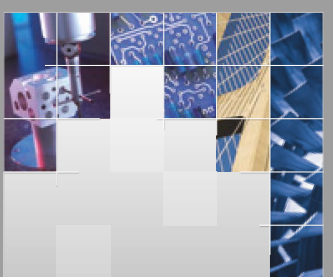

\section{Enfincering}
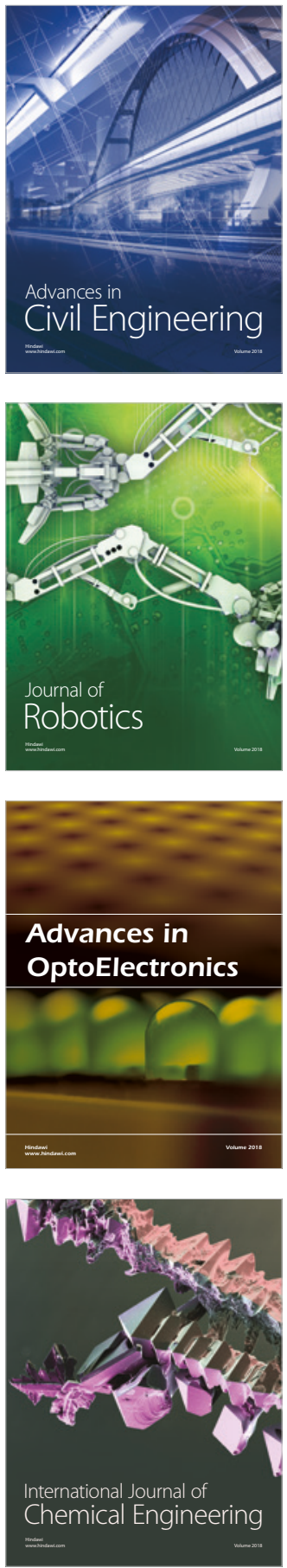

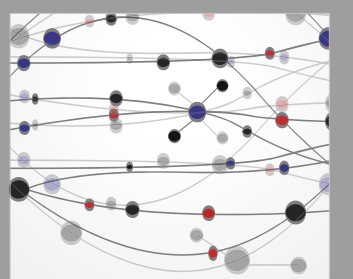

\section{Rotating \\ Machinery}

The Scientific World Journal

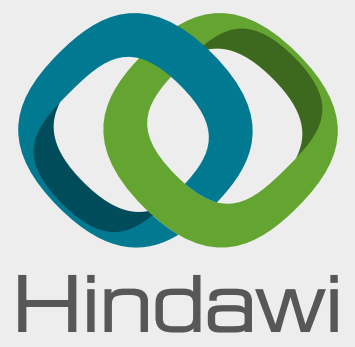

Submit your manuscripts at

www.hindawi.com
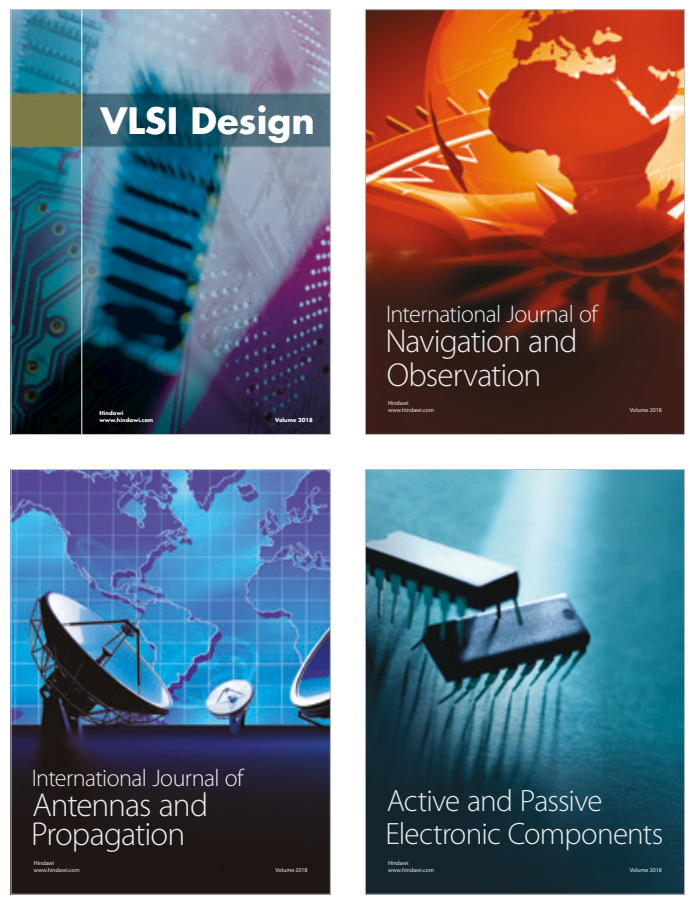
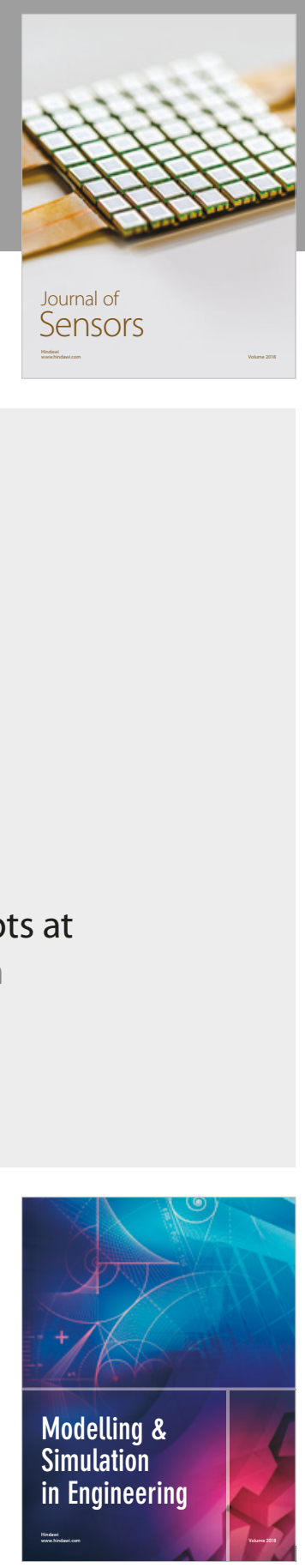

\section{Advances \\ Multimedia}
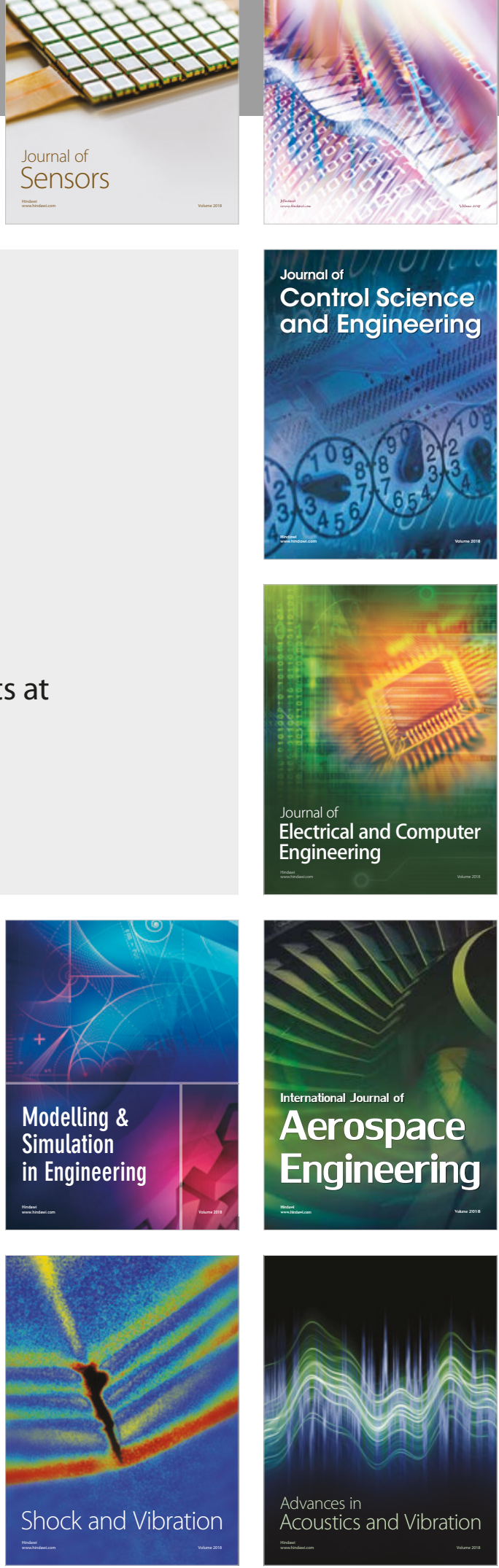